Illinois State University

ISU ReD: Research and eData

Theses and Dissertations

3-29-2019

\title{
The relationship between college health professionals' communicative behaviors, students' satisfaction, and students' perceived quality of healthcare
}

Prince Adu Gyamfi

Illinois State University, adugyamfiprince5@gmail.com

Follow this and additional works at: https://ir.library.illinoisstate.edu/etd

Part of the Communication Commons

\section{Recommended Citation}

Adu Gyamfi, Prince, "The relationship between college health professionals' communicative behaviors, students' satisfaction, and students' perceived quality of healthcare" (2019). Theses and Dissertations. 1113.

https://ir.library.illinoisstate.edu/etd/1113

This Thesis is brought to you for free and open access by ISU ReD: Research and eData. It has been accepted for inclusion in Theses and Dissertations by an authorized administrator of ISU ReD: Research and eData. For more information, please contact ISUReD@ilstu.edu. 


\section{THE RELATIONSHIP BETWEEN COLLEGE HEALTH PROFESSIONALS' \\ COMMUNICATIVE BEHAVIORS, STUDENTS’ SATISFACTION, AND STUDENTS’ PERCEIVED QUALITY OF HEALTHCARE}

\section{PRINCE ADU GYAMFI}

\section{Pages}

In this thesis, a Pearson product-moment correlation was performed using SPSS to analyze the associations between college health professionals' communicative behaviors (instrumental and affective), students' satisfaction, and students' perceived quality of healthcare. Results showed that college health professionals' communicative behaviors positively associated with students' satisfaction and students' perceived quality of healthcare. The implication is that college health professionals need to pay careful attention to how they interact with students at student health service because their interactions can potentially cause either high or low patient satisfaction or perception of quality of healthcare among students. Additionally, this thesis used anxiety/uncertainty management (AUM) theory to investigate how students managed their anxiety and uncertainty about their health issues when they interacted with college health professionals at student health service. The thesis found that students reported using trust, relaxation, and information seeking/giving as strategies to deal with their anxiety and uncertainty about their health issues before and during their interactions with college health professionals. KEYWORDS: instrumental/affective behavior, patient satisfaction, perceived quality of healthcare, college health professionals, student health service, anxiety/uncertainty management (AUM) theory 


\section{THE RELATIONSHIP BETWEEN COLLEGE HEALTH PROFESSIONALS' COMMUNICATIVE BEHAVIORS, STUDENTS' SATISFACTION, AND STUDENTS' PERCEIVED QUALITY OF HEALTHCARE}

PRINCE ADU GYAMFI

A Thesis Submitted in Partial Fulfillment of the Requirements for the Degree of MASTER OF SCIENCE

School of Communication

ILLINOIS STATE UNIVERSITY 
C 2019 Prince Adu Gyamfi 


\title{
THE RELATIONSHIP BETWEEN COLLEGE HEALTH PROFESSIONALS' COMMUNICATIVE BEHAVIORS, STUDENTS' SATISFACTION, AND STUDENTS' PERCEIVED QUALITY OF HEALTHCARE
}

\author{
PRINCE ADU GYAMFI
}

COMMITTEE MEMBERS:

Lance Lippert, Chair

John Hooker

John Baldwin 


\section{ACKNOWLEDGMENTS}

I use this opportunity to first and foremost thank Almighty God for my life! I could not have made it this far without His continuous grace, favor, mercy, and glory. Even in my sinful nature, He has been there with me. God, I am forever grateful and indebted to you! Secondly, I would like to express my heartfelt gratitude to my family, particularly my sweet mother for her continuous support, both financially and in prayers, for my undergraduate and graduate education. Thank you, mum!

Thirdly, I would like to say a big thank you to Dr. Lance Lippert, my thesis committee chair, for your immeasurable mentorship and guidance in successfully completing this thesis. Thank you, Dr. John Hooker, a member of my thesis committee! You patiently and painstakingly taught me and took me through the quantitative stuff including creating my surveys on Qualtrics and analyzing data using SPSS. Dr. Hooker, I am grateful! Thank you, Dr. John Baldwin, a thesis committee member! I owe the tremendous improvement in my scholarly writing to you. Your detailed feedback on my writing skills, not forgetting your hate for passive voices, has been instrumental in completing this thesis. Dr. Baldwin, thank you!

Lastly, I would like to thank all the wonderful and amazing graduate faculty of School of Communication, Illinois State University. I am a proud graduate student because of all of you. Faculty, thank you! I cannot end here without thanking my colleague graduate students and fellow graduate teaching assistants. You guys have shown that indeed no one is an island. I could not have asked for more. Thank you!

P. A. G. 


\section{CONTENTS}

Page

ACKNOWLEDGMENTS

$\begin{array}{ll}\text { CONTENTS ii } & \text { ii }\end{array}$

CHAPTER I: INTRODUCTION 1

Purpose of the Study $\quad 5$

CHAPTER II: LITERATURE REVIEW

$\begin{array}{ll}\text { Student Health Services } & 6\end{array}$

Health Professionals' Communicative Behaviors 99

$\begin{array}{ll}\text { Instrumental Behavior } & 10\end{array}$

$\begin{array}{ll}\text { Affective Behavior } & 11\end{array}$

$\begin{array}{ll}\text { Patient Satisfaction } & 13\end{array}$

Perceived Quality of Healthcare 16

Anxiety/Uncertainty Management (AUM) Theory 18

Parallel Studies Using AUM Theory 23

Hypotheses and Research Questions for Current Study 25

$\begin{array}{ll}\text { CHAPTER III: METHODS } & 28\end{array}$

$\begin{array}{ll}\text { Participants } & 28\end{array}$

$\begin{array}{ll}\text { Demographics } & 28\end{array}$

$\begin{array}{ll}\text { Data Collection } & 29\end{array}$

$\begin{array}{ll}\text { Procedures } & 29\end{array}$

$\begin{array}{ll}\text { Variable and Measures } & 30\end{array}$

College health professionals' instrumental behavior 30 
$\begin{array}{ll}\text { Students' satisfaction } & 31\end{array}$

Students' perceived quality of healthcare $\quad 31$

$\begin{array}{ll}\text { Open-Ended Questions } & 31\end{array}$

$\begin{array}{ll}\text { Data Analysis } & 32\end{array}$

CHAPTER IV: RESULTS FOR QUANTITATIVE DATA 33

Discussions of Quantitative Results 34

Summary of Findings 34

Strengths, Limitations, and Future Research of Quantitative Results 36

$\begin{array}{ll}\text { Conclusion } & 38\end{array}$

CHAPTER V: RESULTS FOR QUALITATIVE DATA 39

$\begin{array}{ll}\text { Trust } & 39\end{array}$

$\begin{array}{ll}\text { Reassurance } & 39\end{array}$

$\begin{array}{ll}\text { Call a Personal Doctor } & 40\end{array}$

$\begin{array}{ll}\text { Information Seeking/Giving } & 41\end{array}$

$\begin{array}{ll}\text { Ask Questions } & 41\end{array}$

Conduct Research $\quad 42$

$\begin{array}{ll}\text { Provide Information } & 42\end{array}$

$\begin{array}{ll}\text { Relaxation } & 43\end{array}$

$\begin{array}{ll}\text { Stay Calm } & 43\end{array}$

$\begin{array}{ll}\text { Stay Positive } & 44\end{array}$

Discussion of Qualitative Results $\quad 44$

Summary of Findings 44 
$\begin{array}{lr}\text { Conclusion } & 50\end{array}$

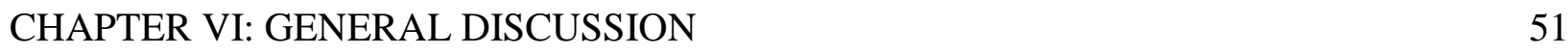

$\begin{array}{ll}\text { Summary of Findings } & 51\end{array}$

Synthesis of Quantitative and Qualitative Findings 53

Strengths, Limitations, and Future Research 53

$\begin{array}{ll}\text { Conclusions } & 54\end{array}$

$\begin{array}{ll}\text { REFERENCES } & 56\end{array}$

APPENDIX A: ONLINE SURVEY QUESTIONNAIRES 68 


\section{CHAPTER I: INTRODUCTION}

Communication plays an invaluable role in health care delivery (Du Pre, 2017; Ruben, 2016; Thornton \& Kreps, 1993; van Servellen, 2009). As Thornton and Kreps (1993) argue, communication helps healthcare providers to gather relevant information "for guiding health care activities and eliciting cooperation in the provision of health care" (p. 1). It is also through communication that healthcare consumers are able to "make their health care needs known and for gathering relevant health information to direct their own health care" (p. 1).

A large body of literature has paid much attention to the aspect of interpersonal communication in healthcare provision, particularly health provider-patient communication (Alli, Maharaj, \& Vawda, 2013; Koemer \& Kilbane, 2008; Mataki, 2000; Ong, De Haes, Hoos, \& Lammes, 1995; Rowland-Morison \& Carroll, 1990). Evidence shows that effective communication between healthcare providers and patients can promote patient satisfaction and the delivery of perceived quality of healthcare (Du Pre, 2017; Thornton \& Kreps, 1993; Wong \& Lee, 2006). A healthcare provider or professional refers to "anyone working in healthcare, whether in hospitals or in the community, who comes in contact with clients or whose work influences care" (Cheng, 2004, p. 72). For the purpose of the present study, healthcare professionals include doctors, nurses, physician assistants, nurse assistants, lab attendants, and pharmacists who deliver healthcare services to patients in hospitals.

In traditional healthcare settings (off-campus health centers), research shows that healthcare professionals' communicative behaviors have an impact on patient satisfaction (Bensing, 1991; Bertakis, Roter, \& Putman, 1991; Chen, Zou, \& Shuster, 2017; Cousin, Mast, Rotter, \& Hall, 2012; Hooker, Potts, \& Ray, 1997; Ranjbarian, Emami, \& Ranjbarian, 2012) and perceived quality of healthcare delivery (Bensing \& Dronker, 1992; Ghahramanian, Rezaei, 
Abdullah, Sheikhalipour, \& Dianat., 2017). Health communication scholars have divided these communicative behaviors into instrumental and affective behaviors and have extensively examined them. While the instrumental behaviors focus on accomplishing the technical, medical goals pertaining to solving health problems through gathering information, asking questions, and counseling, the affective behaviors deal with achieving the socio-emotional goals such as showing concern and empathy, legitimizing feelings, and showing approval (Nelson, Miller, \& Larson, 2010; Roter \& Larson, 2001, 2002). According to Roter and Larson (2001), affect may also be expressed implicitly through voice tone, general positive impression (friendliness), or negative emotion (anxiety or irritation).

As Du Pre (2017) argues, healthcare professionals' communication, not their technical skills, is more closely connected to patient satisfaction because patients find it difficult to judge the technical skills of healthcare professionals. That said, patients feel more satisfied when healthcare professionals show concern about and respect for them and "have empathy for what they are feeling" (p. 79). Also, research shows that perceived quality of healthcare services has a direct relationship with healthcare professionals' communication. In their study, Ghahramanian et al. (2017) found that lack of empathy and attentiveness to patients' needs resulted in low ratings of perceived quality of healthcare delivery. This indicates the relationship between healthcare professionals' communication and patients' perceived satisfaction and quality of healthcare, justifying, therefore, the large body of literature conducted in this area of providerpatient communication studies in the traditional healthcare delivery settings.

Substantial research has also investigated students and college health services (Allred, Turner, David, DeLozier, \& Strikas, 2005; Birch \& Golbeck, 2015; Halstead, Williams, Gattamorta, \& Gonzalez-Guarda, 2017; Spotts, 2017; Zakletskia, Wilson, \& Fleming, 2010), but 
not enough attention has been paid to students' interaction with healthcare professionals at college health centers. Specifically, little is known about the relationship between health professionals' communicative behaviors (instrumental and affective), students' satisfaction and perceived quality of healthcare at student health services on college campuses. Few studies are related to students' perceived satisfaction and quality of healthcare in college health settings. One study looked at how healthcare professionals at a university health clinic could predict patient satisfaction (Hailey, Pargeon, \& Crawford, 2000), but this study did not examine students' actual perception of satisfaction. The other study examined the impact of health providers' interpersonal skills on patient satisfaction (Campbell, Auerbach, \& Kiesler, 2007). These interpersonal skills included only friendliness and dominance. However, healthcare providers' communicative behaviors are not limited to friendliness and dominance. Another study evaluated students' perception of the quality of healthcare provided at the student health services (Canel \& Fletcher, 2001). This study did not specifically look at the relationship between communication and perceived quality of healthcare. Therefore, the present study intends to fill this gap.

Perrault (2018) indicates that campus health centers are convenient locations where college students can seek affordable healthcare services. Adding to this, Turner and Keller (2015) suggest that students are indeed utilizing these health facilities on university campuses. According to Perrault, health professionals at the campus health centers can provide similar levels of primary care that professionals at off-campus health centers can offer. Interestingly, Perrault (2018) suggests that physician assistants and nurse practitioners provide more primary care than physicians at campus health centers. The implication is that unlike traditional health 
settings (off-campus healthcare centers), students are likely to interact more with physician assistants and nurses than physicians at campus health centers, justifying the need for an inquiry.

Babrow and Mattson (2011) contend that most health communication scholarship is not informed by theories, thereby stressing that "theoretically informed/informing work is of the greatest importance in this late or postmodern age" (p. 18). Specifically, according to Bensing (1991), fewer studies about doctor-patient communication have a theoretical framework. In her study, Bensing suggests that patients visit doctors with specific needs seeking medical solutions. She classifies these needs as "the resolution of uncertainty problem" and "the resolution of anxiety problem" (p. 38). She explains that while the uncertainty problem reflects cognitive needs, the anxiety problem reflects emotional needs; but she also suggests that both uncertainty and anxiety problems are interrelated. She indicates that doctors' communicative behaviors may cause patients' initial uncertainty and anxiety levels either to increase or decrease.

Some studies (Roberts \& Aruguette, 2000) have employed socio-interaction theory to examine the relationship between doctors' affective behaviors and patient satisfaction. Sociointeraction theory posits that, apart from medical needs, patients visit doctors with the desire to get relief from anxiety (Ranjbarian, Emami, \& Ranjbarian, 2012). Patients feel less anxious when their doctors show concern by listening and providing reassurance. Ranjbarian et al. also used reciprocity theory to investigate doctors' instrumental or task behaviors and have established their relationship with patient satisfaction. Reciprocity theory states that patients' instrumental behaviors such as compliance and satisfaction should reciprocate doctors' instrumental behaviors such as information giving (Ranjbarian et al.). However, the researchers used each theory separately to study each aspect of doctors' communicative behaviors. Additionally, these theories fell short in explaining how patients could manage their anxiety and 
uncertainty during medical encounters. Hence, the current research intends to use Gudykunst's anxiety/uncertainty management (AUM) theory to explore how students manage their levels of anxiety and uncertainty during their communication encounters with healthcare professionals at student health services.

\section{Purpose of the Study}

The purpose of this study is to investigate the relationship between college health professionals' communicative behaviors (instrumental and affective), students' satisfaction, and students' perceived quality of healthcare at university campus health centers because there is little scholarship in this area. Moreover, unlike in traditional healthcare settings (i.e., off-campus health centers), students interact more with physician assistants and nurses than physicians at the campus health centers, justifying the need for an inquiry. Finally, the present study will adopt AUM Theory to explore the strategies that students use to manage their anxiety and uncertainty during their communication encounters with college health professionals at student health services. 


\section{CHAPTER II: LITERATURE REVIEW}

\section{Student Health Services}

Student health services are present across US on over 4,400 campuses (American College Health Association, 2010) and are convenient locations on campuses where college students can seek affordable healthcare (Perrault, 2018). Many of these student health services are accredited by the Joint Commission and Accredited Association for Ambulatory Health Care (American College Health Association, 2010). Student health services not only provide medical care but also manage serious chronic conditions and promote healthy needs (Skorton \& Altschuter, 2013; Turner \& Keller, 2015). Health providers at these student health services can provide primary healthcare similar to what is provided at off-campus health centers (Perrault, 2018). Lemly, Lawlor, Scherer, Kelemen, and Weitman (2014) argue that student health services deliver quality healthcare on campuses.

College students are considered to be a healthy population, but they have some health needs that are similar to those encountered in general medical practices (Grace, 1997; Skorton \& Altschuter, 2013) and that can be minimized with timely attention and intervention (Garcia, Lechner, Frerich, Lust, \& Eisenberg, 2014). As mostly young adults, college students have some special issues such as alcohol and drug abuse, depression, sleeping and eating disorders, anxiety, attention deficit or hyperactivity disorder, assault (sexual and physical), stress, homesickness, and relationship difficulties, which need healthcare attention (American College Health Association, 2016). These health needs potentially affect individual students' academic performance. In an executive summary, 57\% college students sampled (total sample of 27,787) reported being diagnosed or treated by health professionals at student health services (American 
College Heath Association, 2016), indicating that students are indeed utilizing the health services on campuses (Turner \& Keller, 2015).

Based upon previous literature, it is possible to assume that, if student health services are providing some healthcare services that are similar to those at other medical settings such as family practice clinics, hospitals, and oncology wards, there is no need to study college health settings since much patient-providers communication and patient satisfaction and quality of healthcare studies have already been carried out in general medical settings. However, student health services provide certain contexts that are unique (Hailey et al., 2000), thereby justifying the present inquiry. One aspect of college student health services is that college students are the population that most likely do not have their own health insurance coverage and are mostly covered by their parents' insurance (Garcia et al., 2014; Grace, 1997; Hailey et al., 2000). According to Grace (1997), the parents' managed care plans, near their homes, cannot pay for medical care provided outside their service areas. The implication is that most college students are likely to enroll in the health insurance coverage provided by colleges and universities so that they can access healthcare on campus.

Turner and Keller (2015) also indicate that "groups traditionally under-represented in US healthcare systems are utilizing campus resources at robust rates" (p. 536). This implies that most under-represented groups that are not captured in previous studies conducted in traditional health settings can be investigated at student health services on college and university campuses. Additionally, students can only access campus health services as long as they continue to enroll as students, but patients seen in traditional medical settings may not experience such a limitation (Hailey et al., 2000). College students may have fewer options than other patients (in traditional health settings) in choosing specific health providers to see for medical treatment. As a result, it 
may be difficult for college students to establish a long-term relationship with specific health providers (Hailey et al), which most likely influences interactions between them during any medical encounters.

Literature shows that many scholars have studied wellness promotion within academia (Baldwin, Towler, Olivier, \& Datta, 2017), students' preferences for health providers on campus (Garcia et al., 2014), and quality of healthcare services delivered at student health service (Canel \& Fletcher, 2001; Canel \& Kadispasaoglu, 2002). However, few studies have examined students’ interaction with health professionals at student health services. Specifically, three studies (Campbell et al., 2007; Canel \& Fletcher, 2001; Hailey et al., 2000) are related to the present study. Unfortunately, these studies examined aspects of health professionals' interpersonal skills such as friendliness and dominance and their association with patient satisfaction. Also, these studies did not investigate students' perception of satisfaction. Lastly, the relationship between perceived quality of healthcare and health professional communication was not evaluated. Therefore, the present study intends to fill these gaps.

Additionally, this study will illuminate health communication scholar and trainers' understanding of how students' perception of college health professionals' communicative behaviors is related to student satisfaction and perceived quality of healthcare delivered at students health service on college and university campuses. The findings are expected to guide any communication skills training program that will be more specific to health professionals working at student health services on college and university campuses. In this regard, I will review existing literature on healthcare professionals' communicative behaviors, patient satisfaction, perceived quality of healthcare, and Anxiety/Uncertainty Management (AUM) theory to establish the need for the current inquiry. 


\section{Health Professionals' Communicative Behaviors}

A health professional refers to "anyone working in healthcare, whether in hospitals or in the community, who comes in contact with clients or whose work influences care" (Cheng, 2004, p. 72). For the purpose of the present study, healthcare professionals include doctors, physician's assistants, nurses, nurse assistants, lab attendants, and pharmacists who deliver healthcare services to patients in university campus health centers. Communication is instrumental in decision-making, improving health outcomes, and raising patient satisfaction (Du Pre, 2017). At the heart of quality patient care is effective communication skill (Du Pre). Because communication skills are crucial in medical encounters, medical and health training institutions are providing more communication skills training for health providers, but current medical education curriculums are not providing adequate communication training (Wanzer, BoothButterfield, \& Gruber, 2004).

As Hersh, Godecke, Armstrong, Ciccone, and Bernhardt (2016) argue, "Patients are more cognitively and socially active when wards provide an 'enriched environment' as compared to standard care" (p. 610). This 'enriched environment' means that patients are motivated to use their language skills to freely communicate with health providers. As a result, extensive studies have been conducted in patient-provider communication. However, doctors' communicative behaviors have received more attention. Hersh et al. (2016) suggest that nurses need more effective communication skills because they interact more with patients than other health providers. In their study, patients appreciated nursing interactions that were respectful, friendly, and humorous.

Some scholars (Helitzer, LaNoue, Wilson, de Hernandez, Warner \& Roter, 2011; Wanzer et al., 2004) describe health providers' communicative behaviors as patient-centered 
communication that impacts patient satisfaction, compliance, and diagnosis or treatment. These communicative behaviors include eliciting patient perspectives, responding to patient concerns, giving information, partnership building, and engaging patient decision-making (Helitzer et al., 2011). Hall, Roter, and Katz (1988) argue that:

One useful way to conceptualize patient outcome and provider behaviors is in terms of task-socioemotional distinction... Such conceptualization serves a heuristic purpose; it provides a two-dimensional framework that separates physician from patient behaviors, as well as task from socioemotional domains. This allows a reasonable rationalization of great number of variables in the field and suggests various testable hypotheses about linkages among them. (p. 667)

This argument has influenced scholars to classify health providers' communicative behaviors into instrumental and affective behaviors. Consequently, some health communication scholars have studied instrumental and affective behaviors' impact on patient satisfaction and perceived quality of healthcare. Instrumental and affective behaviors are variables examined in the present study. Bensing and Dronker (1992) stress that both instrumental and affective behaviors are equally important in medical communication because patients have two basic needs, "the need to know and understand" and "the need to feel known and understood" (p. 283). The conceptualization of instrumental and affective behaviors differs among authors.

\section{Instrumental Behavior}

Ong et al. (1995) indicate that the instrumental focused exchange has received much research attention. Instrumental behavior, which is also called task-focused behavior, relates to the cognitive domain and is cure-oriented. According to Ranjbarian et al. (2012), this behavior accomplishes technical medical goals such as giving information, asking questions, and 
counseling. Roter and Larson (2002) define instrumental behavior as "technically based skills used in problem solving that comprise the base of the 'expertness' acquired through professional medical education and for which a physician is consulted" (p. 243). Instrumental behaviors include giving information; asking questions; and giving direction, technical competence, and counseling (Bensing \& Dronker, 1992; Hall et al., 1988; Roter \& Larson, 2002). Hall et al. (1988) note that asking question pertains to information seeking and is classified into four kinds of questions: opinion, understanding, suggestions, and requesting. Health providers ask both closed- and open-ended questions (Hall et al., 1988). Roter and Larson (2002) indicate that “patients' communication may be viewed in a parallel fashion" (p. 244). Therefore, instrumental behaviors can be seen in patient question-asking and information giving (Roter \& Larson).

\section{Affective Behavior}

Affective behavior, which is also known as socio-emotional behavior, relates to the emotional domain and is care-oriented (Ong et al., 1995). This behavior accomplishes interpersonal goals such as showing concern and empathy, legitimizing feelings, and showing approval (Hall et al., 1988; Nelson et al., 2010; Ranjbarian et al., 2012; Roter \& Larson, 2001). Roter and Larson (2002) suggest that affective behaviors are not learned in medical schools. According to Ong et al. (1995), different authors have categorized affective behaviors in different ways. For example, some have categorized affective behaviors as social behaviors, which include personal remarks, jokes, showing approval, and agreement. Others have categorized affective behaviors as verbal attentiveness (e.g., showing agreement, paraphrasing and reflecting patients' messages, legitimizing patients' behaviors or feelings, and showing partnership) and showing concern including showing worry and giving reassurances (Ong et al.). Hall et al. (1988) categorize affective behaviors into partnership building, social conversation, 
positive and negative talk, and interpersonal competence. Partnership building involves health providers recognizing patients as equal partners in the medical relationship to motivate patient participation. Health providers can encourage partnership building in two ways. First, providers can solicit patient inputs in decision making. Second, providers should not be seen as controlling or dominating the interaction. Hall et al. define social conversation as "conversation that is nonmedical and is not problem-focused" (p. 664). Roter and Larson (2002) categorize affective behaviors to include "exchanges with explicit socio-emotional content related to the building of social and emotional rapport, for instance, the use of social amenities, empathy, concern, or reassurance" (p. 244). Although these categorizations provide a clearer understanding of the various aspects of affective behaviors, these aspects duplicate one another, so I will examine them together as affective behaviors.

Previous research has found that instrumental and affective behaviors have significant associations with patient satisfaction and perceived quality of healthcare such as patient compliance (Helitzer et al., 2011). In fact, Uitterhoeve et al. (2009) note that health providers' affective behaviors are strong predictors of patient satisfaction. These communicative behaviors have been studied among nurses and physicians. Additionally, instrumental and affective behaviors have been studied in different health contexts such as adult and pediatric primary care, emergency medicine, obstetric and gynecology, oncology, end of life and palliative care, surgery, housing, podiatry, genetic counseling, family planning services, and dentistry (Roter \& Larson, 2002). For instance, Uitterhove et al. (2009) found that patient satisfaction was correlated with nurses' cue responding. These cues include the use of open directive questions, eliciting of emotional concerns, clarification of emotional aspects, summarizing, and screening questions. The cue responding emphasizes patients' feelings. 
Hall et al. (1988) found that patient satisfaction was related to greater technical and interpersonal competence, more partnership building, more immediate and positive non-verbal behavior, more social conversation, more positive talk, less negative talk, and more overall communication. Ranjbarian et al. (2012) also studied instrumental and affective behaviors in dentistry. They found a positive significant correlation between dentists' affective behavior and patient satisfaction and concluded that "dentists' socio-emotional behaviors can relieve patient's anxiety and cause feel of trust and satisfaction" (p. 322). However, little is known about patient satisfaction in student health services on college and university campuses. Thus, the present study intends to investigate the instrumental and affective behaviors at the student health services.

\section{Patient Satisfaction}

Satisfaction is "the human experience of being filled and enriched by an experience" (Safaan, Elkhouly, \& Ibrahem, 2015, p. 13300). Patient satisfaction, including the relationship between patients and healthcare providers in medical settings (Huy, Dung, Thang, \& Hanh, 2017) is a significant contributing factor in improving health care process (Dunsch, Evans, Macis, \& Wang, 2018). Patient satisfaction is broadly the expectations of a patient and whether those expectations are met or not (Sharma, 2017). Evans, Stanley, and Burrows (2009) better define patient satisfaction as "the individual's evaluation of a range of aspects to immediate health care, together with an overall evaluation of health-care event, based on the individual's expectations and previous health-care encounters" (p. 159).

Satisfaction is a key indicator in determining the quality of healthcare delivery (Ali, 2016; McMullen \& Netland, 2013; Safaan et al., 2015; Verulava, Jorbenada, Karimi, Dangadze, \& Barkalaia, 2018; Xesfingi \& Voikis, 2016) as well as determining the response to patients' 
needs (Huy, et al., 2017). According to Huy et al. (2017), satisfaction influences patient retention, clinical outcomes, patient loyalty, and consistent profitability. It also affects "the efficient, patient-centered, and efficient delivery of quality in health care" (p. 252). Because health provider-patient communication influences patients' perception of satisfaction, Koermer and Kilbane (2008) define patient satisfaction as "the response patients have toward their physicians based on perceptions of affective, cognitive, and behavioral elements of the physician's behavior" (p. 72).

A large body of research has examined the influence of health provider-patient communication on patient satisfaction (Dutta-Bergman, 2005; Moore, Wright, \& Bernard, 2009). Moore, Wright, and Bernard (2009) suggest that patients may not be educated enough to be able to evaluate physicians' technical or task behaviors but may be able to evaluate physicians' affective behaviors such as patience, concern, empathy, and attentiveness. Consequently, most scholarships deal with the association between influence of affective behaviors and patient satisfaction. For example, Uitterhoeve et al. (2009) found that nurses' affective behaviors such as eliciting emotional concerns, clarifying emotional aspects, and empathy predicted patients' satisfaction.

There appears to be a contradiction in the literature as to which health professionals' communicative behaviors are more important in predicting patient satisfaction. Some studies (Koermer \& Kilbane, 2008; Moore et al., 2009) suggest affective behaviors as more important, while other studies indicate that "patients tend to be most satisfied with understanding their treatment plan, physician honesty, and being understood, and report being least satisfied with physician information concerning caring for their illness" (Sparks, Villagran, Parker-Raley, \& Cunningham, 2007, p. 182). Surprisingly, most studies have focused on doctors; few studies 
have focused on other health professionals, particularly nurses, whom literature suggests interact more with patients than other health professionals do (Hersh et al., 2016), evidencing therefore the need for more investigation into the communication of other health professionals. For example, Wanzer et al. (2004) found that nurses' communicative behaviors such as empathy and listening predicted patients' satisfaction. This finding, they suggest, might be due to the "preparatory role that nurses often play in health interviews" (p. 378).

Although a considerable amount of literature has evaluated the association between health professionals' communication and patient satisfaction in traditional health settings, similar studies are lacking in student health services, which deal with the unique population of college students with different characteristics. Only two studies are directly related to the present work. One evaluates the effect of the interpersonal relationships between health providers and college students on patients' satisfaction (Campbell et al., 2007). The interpersonal relationship is limited to control (to dominate, take charge) and affiliation (to be friendly and caring). Campbell et al. found that heath providers are willing to share information with patients and involve them in decision making, which are associated with higher patient satisfaction scores. They also found that the interpersonal variables (specifically, control and affiliation) positively affected satisfaction. Campbell et al. examined only friendliness and dominance variables, but other interpersonal variables such as listening, asking questions, showing approval and partnership, empathizing, and verbal attentiveness are not included in their examination. The other related study (Hailey et al, 2000) looks at how the communicative behaviors of health providers at a university health center can predict patient satisfaction. The present study is interested in patients' (students) perception of satisfaction, in part, as related to their perception of quality of healthcare. 


\section{Perceived Quality of Healthcare}

In organizational research, quality is "the ability of an organization to meet or exceed customer expectations" (Verulava et al., 2018). According to Sharma (2017), quality has several dimensions, and different scholars use different dimensions to determine quality of healthcare. Performance, features, durability, serviceability, response, aesthetic, and reputation are some of the dimensions; service quality is the most commonly used dimension in determining quality of healthcare (Atinga, Abekah-Nkrumah, \& Domfeh, 2011). There are two forms of service quality: technical and functional quality (Atinga et al., 2011; Verulava et al., 2018). While technical quality refers to the accuracy of medical diagnosis and procedures, functional quality refers to how healthcare services are delivered to patients. Because functional quality is easy for patients to recognize, it has been identified as the primary predictor of perceived quality of healthcare (Verulava et al, 2018).

Van Servellen (2009) defines quality of healthcare as "the degree to which health services for individuals and populations increase the likelihood of desired health outcomes and are consistent with current professional knowledge" (p. 4). As Sharma (2017) argues, quality of healthcare can be measured in two ways: ratings provided by patients and the ones based on clinical performance and testing. Patients ratings determine the expectations of patients and whether those expectations are met or not. Clinical performance measures focus on the ability of healthcare organizations to prevent and treat illnesses. Communication is vital in quality of health care (van Servellen, 2009); as the quality of communication improves, patient health outcomes also improve, suggesting a positive and direct relationship between these aforementioned variables. 
Most studies have investigated influence of service quality on patient satisfaction (Ahenkan \& Adu-Adjei, 2017; Atinga et al., 2011; Badri, Attia, \& Ustadi, 2009; Dunsch et al., 2018: Verulava et al., 2018); but few studies have focused on the relationship between health providers' communicative behaviors and patients' perceived quality of healthcare (Bensing, 1991; Bensing \& Dronker, 1992). Bensing (1991) examined the relationship between communication variables and quality of care. Specifically, she restricted her study to quality of psychosocial care. She defined psychosocial care as "receptiveness for and treatment of the (etiological and consequential) non-somatic aspects of the presented health problem" (p. 1303). The study was conducted in two parts. The first part assessed the quality of psychosocial care by using video recordings of real doctor-patient communication. The video recordings enabled Bensing to assess both verbal and nonverbal behaviors.

The second part of Bensing's (1991) study, which is more relevant to the present study, examined the relationship between doctor-patient communication, patient satisfaction, and quality of healthcare. The doctor-patient communication variables were grouped into affective behaviors, systematic and purposive behaviors, and patient-centered behaviors. Affective behaviors included shown interest, nonverbal attention, encouraging, and verbal empathy. Systematic and purposive behaviors included clarifying, structuring, and purposive probing. Patient-centered behaviors included diagnostic phase and therapeutic phase. The results showed that affective behaviors had strong predictive power on quality of psychosocial care. Specifically, nonverbal behaviors such as eye contact and shown interest were stronger in predicting quality of psychosocial care. Her findings suggest that affective behavior is more likely than instrumental behavior to be a predictor of quality of healthcare 
Bensing and Dronker (1992) also evaluated the relationship between instrumental and affective behaviors and quality of healthcare. They recruited twelve experienced general practitioners (GP) to assess quality of care based on video-taped consultations. Quality of care variables were medical care, psychosocial care, and management of the GP-patient relationship. Their findings showed a positive relationship among the four instrumental behaviors (giving information, asking questions, counseling, and giving directions) and each of the three quality of care variables. Verbal attentiveness of the affective behavior had the strongest relationship with all the quality of care variables. However, scholarship is lacking on the relationship between health professionals' communicative behaviors and students' perception of quality of healthcare at student health services, evidencing the need for an inquiry.

Bensing (1991) notes that patients are already uncertain and anxious about their health problems before they even see health professionals. Patients' uncertainty and anxiety levels are likely to either increase or decrease depending on the outcome of their interaction with health professionals during medical encounters. Anxiety/Uncertainty Management (AUM) theory provides a theoretical framework to explicate how students can manage their anxiety and uncertainty during their medical encounters at student health services.

\section{Anxiety/Uncertainty Management (AUM) Theory}

Berger and Calabrese's (1995) uncertainty reduction theory has largely influenced the introduction of Anxiety/Uncertainty Management (AUM) Theory (Gudykunst, 2005). This theory has gone through several stages of development and refinement (Gudykunst, 1988, 1995, 2005). The final version of the theory helps to explain interpersonal and intergroup communication effectiveness (Gudykunst, 2005). AUM Theory has five key foundational concepts: stranger, uncertainty, anxiety, effective communication, and mindfulness. I will 
provide brief explanation about these concepts and illustrate their application in patient-provider communication and utility for this study.

The main goal of this theory is to explain how individuals use effective communication to reduce the amount of their uncertainty and anxiety. According to Gudykunst (2005), effective communication occurs when a person's interpretation of the meaning of a message is similar to what was intended. Misunderstanding often happens when one interacts with strangers because in most cases, one uses his or her frame of reference to interpret strangers' messages. The stranger concept signifies both the idea of nearness and remoteness (Gudykunst, 1995). The idea of nearness means physically close, but remoteness signifies that communicators have differences in values and way of doing things. Because strangers are ignorant about the personalities of each other, they become anxious and uncertain in their interactions (Gudynkunst, 1995). Also, they cannot predict with some degree of accuracy of what to expect from the interaction.

Uncertainty affects the way one thinks about a stranger. Uncertainty, a cognitive variable, occurs when one cannot predict and explain strangers' attitudes, feelings, values, thoughts, and behaviors (Gydunkunst, 2005). According to Gudykunst (1995), everyone has maximum and minimum thresholds for uncertainty. For instance, if an individual's uncertainty is higher than his or her maximum threshold, he or she is not confident in predicting and explaining strangers' behaviors and may decide to end the interaction or gather more information to continue the interaction. If one's uncertainty is lower than his or her minimum threshold, he or she is too confident in predicting or explaining strangers' behaviors, which may lead to miscommunication because he or she may not be listening or bored. As a result, to have the confidence to predict 
and explain strangers' thoughts, attitudes, and behaviors in any given interaction, one has to keep his or her uncertainty between the minimum and maximum thresholds.

Anxiety, an affective variable, relates to the way one feels about a stranger. Anxiety emanates from "feeling uneasy, tense, worried, or apprehensive about what might happen" in one's interaction with strangers (Gudykunst, 1995, p. 12). Similar to uncertainty, everyone has maximum and minimum thresholds for anxiety, which influence one's interaction with strangers. Trust and fear affect the level of anxiety one experiences when communicating with strangers (Gudynkunst, 2005). For instance, if there is trust, one expects positive outcomes from interacting with strangers. But if there is fear, one expects negative outcomes from interacting with strangers.

As indicated above, one cannot communicate effectively with a stranger if their anxiety and uncertainty are above or below their maximum and minimum thresholds respectively. For effective communication, one needs to maintain their anxiety and uncertainty at the optimal level, that is, managing anxiety and uncertainty within the maximum and minimum thresholds. The optimal level of uncertainty is when one believes they are able to predict a stranger's behavior and at that same time recognizes that they cannot accurately explain that behavior. Also, the optimal level of anxiety is when one feels comfortable communicating with a stranger, yet they still have enough anxiety not to be complacent in their interaction with a stranger (Gudynkunst, 2005). According to Gudykunst, mindfulness mediates the relationship between ability to manage anxiety and uncertainty and effective communication in that "when our anxiety and our uncertainty are between our minimum and maximum thresholds, we can communicate effectively with strangers when we are mindful" (p. 306). 
Mindfulness is awareness of one's communicative behavior when communicating with others. This concept involves creation of new categories, openness to new information, and awareness of more than one perspective (Gudykunst, 1995). For instance, if one is mindful, he or she tends to create new categories that are more specific to strangers' behaviors. But if one is mindless, he or she tends to use broad categories such as gender, religion, age, or culture to predict strangers' behaviors. Additionally, if one is mindful, he or she is consciously open to new information including subtle differences emanating from his or her current interaction with strangers. But if one is mindless, he or she will use the same or previous information to predict strangers' behaviors.

As Bensing (1991) argues, patients are already uncertain and anxious about their health problems before they even meet their doctors. For a better explanation, Checton, Greene, Magsamen-Conrad, and Venetis (2012) note that people are very uncertain about their illnesses, particularly when they are dealing with chronic diseases such as diabetes, arthritis, and cardiovascular disease. According to the authors, people's uncertainty about their illnesses may emanate from "the nature of the illness, an unknown future, perceived stigma, lack of information or social support, conflicting diagnosis form health providers, and the development of new symptoms" (p. 115). The implication is that, since patients are already uncertain about their health problems, the fact of meeting health professionals, who are strangers, will further increase patients' uncertainty. Anxiety and uncertainty are likely to fluctuate depending on the outcome of the interaction between patients and health providers.

In medical encounters, patients and health providers are strangers to each other. Even though one may visit his or her personal doctor, they are still strangers to each other because of their differences in age, education, knowledge, power, income, values, beliefs, religion, or 
political interests. These differences can potentially influence patients' ability to accurately predict and explain doctors' communicative behaviors. For instance, if a patient cannot predict with some degree of accuracy of a doctor's communicative behavior, his or her uncertainty will increase, leading to miscommunication. This high uncertainty will cause the patient to feel more anxious. The situation becomes more complicated when the doctor does not provide enough information to help the patient to reduce his or her uncertainty about the latter's health problem or if the doctor does not allow the patient to speak freely to feel less anxious.

Moreover, if a patient's uncertainty about his or her health problem is higher than his or her maximum threshold, he or she is not confident in predicting accurately and explaining the doctor's communicative behavior and may decide not to speak during the medical encounter or try to gather more information from the doctor, so he or she can speak. And if a patient's uncertainty is below the minimum threshold because he or she knows the doctor well enough, he or she is over-confident in predicting and explaining the doctor's behavior and may not be listening attentively to the doctor, causing miscommunication. Additionally, if a patient is mindful about the interaction, he or she will create new categories that are more specific to the doctor's behavior so that he or she can predict accurately the doctor's communicative behavior to reduce both his uncertainty and anxiety. But if a patient is mindless because he or she is, for example, older than the doctor, he or she will use broader category such as age to predict the doctor's behavior. Some studies (Hammer, Wiseman, Rasmussen, \& Bruschke, 1998; Miller \& Samp, 2007; Ni \& Wang, 2011; Whitaker, 2013) have employed AUM theory to explore how people negotiate their anxiety and uncertainty to communicate effectively in contexts such as education, organizations, and cultures. 


\section{Parallel Studies Using AUM Theory}

Hammer et al. (1998) analyzed how international students managed their anxiety and uncertainty in a host culture (i.e., United States of America). The researchers found that an increased intimacy with and greater attraction to host nationals were significantly related to an increased understanding of host nationals and their culture. This implies that interpersonal relationships with host nationals play a significant role in international students' increased understanding and satisfaction living in the host culture. Because of their increased understanding of the host culture, international students gained knowledge of the host culture, which enabled them to significantly reduce their uncertainty about the host culture. They also found that the host nationals' positive attitudes towards international students helped the latter to feel more comfortable in the host society. However, the authors found that information gathering strategies and language proficiency had no relationship with uncertainty or anxiety.

Combining AUM Theory and Theories of Planning, Miller and Samp (2007) investigated the notion of mindfulness in intercultural interaction. Specifically, they evaluated the content and complexity of plans one generates in anticipation of interacting with another from a different culture. The authors found that the content and complexity of plans prior to interaction in intracultural situations was not different from those in intercultural situations. Their findings revealed that mindfulness did not have any influence on one's attributional confidence (the inverse concept to uncertainty—that is, greater attributional confidence means lower uncertainty) and anxiety—but they found a positive association between mindfulness and emotion-related anxiety. The researchers attributed these contradictory findings to the fact that mindfulness might not have an integral influence on uncertainty and anxiety in intercultural encounters. 
Others have utilized AUM Theory in educational contexts. While Ni and Wang (2011) examined whether anxiety and uncertainty mediated the effects from cultivation strategies to relational outcomes, Whitaker (2013) investigated students' perception of community formation and maintenance as an anxiety mechanism before, during, and after a mandatory on-campus orientation for an online Master of Library Studies program. Whitaker focused more on anxiety management. Although Ni and Wang's (2011) study was in an educational context, it centered around organization-public relations, that is, how universities related and communicated with their international publics (international students). The cultivation strategies included access, positivity, assurance of legitimacy, openness, shared networks, and sharing of tasks; the organization-public relations (OPR) outcomes included control mutuality, trust, satisfaction, and communication.

$\mathrm{Ni}$ and Wang (2011) found access and shared networks affecting all OPR outcomes through the mediation effects of either anxiety or uncertainty. The implication is that an increased access to organizational information and decision making will reduce individuals' uncertainty, which contributes to improved relational outcomes. The researchers also found that assurance of legitimacy and sharing of tasks affected OPR outcomes through mediation and direct effects. This finding suggests that when one feels a sense of entitlement in decision making process, their emotional confidence in and commitment to their organization increase. Positivity had only direct effect on trust and satisfaction, -but the openness strategy did not have any effect on relational outcomes.

Whitaker (2013) found that respondents were more motivated to interact when they perceived that strangers would interact positively and were interested in interacting as well. Respondents felt more comfortable when their interaction with strangers remained dignified, 
respectful, and moral. According to respondents, the respect between strangers and themselves enabled them to communicate effectively with strangers. Additionally, respondents shared common language and the perception that their knowledge about how strangers would react enabled them to reduce their anxiety, which ensured effective communication with strangers. Respondents felt more comfortable when they perceived that they had social power in their interactions with strangers; but they did not reveal feeling uncomfortable when they interacted with strangers with higher social power such as university officials including faculty.

Despite AUM theory's heuristic value in intercultural and educational contexts, it has hardly been applied in health communication, particularly patient-doctor communication, to help explain how patients manage their anxiety and uncertainty when interacting with health providers. Previous research shows that patients are already anxious and uncertain about their health problems even before they see health providers. During medical encounters, anxiety and uncertainty are likely to change depending on the outcome of the interaction between patients and health provider. As earlier indicated in the above discussion, AUM theory offers a framework to help better explain how college students are managing their anxiety and uncertainty during their encounters with health professionals at student health services.

\section{Hypotheses and Research Questions for Current Study}

Evidence shows that a large body of literature has studied the relationship between health professionals' instrumental and affective behaviors, patient satisfaction, and perceived quality of healthcare in traditional medical settings such as family practice clinics, hospitals, and oncology wards. Surprisingly, previous research (Bensing, 1991; Bensing \& Dronker, 1992) examining the relationship between health professionals' communicative behaviors and perceived quality of healthcare is dated, calling for a fresh investigation. Despite the unique characteristics of college 
student population, little is known about the relationship between college health professionals' communicative behaviors, students' satisfaction, and perceived quality of healthcare, therefore justifying this inquiry. The present study seeks to test these hypotheses:

H1: Students' perception of college health professionals' communicative instrumental behaviors will be positively associated with students' satisfaction.

H2: Students' perception of college health professionals' communicative affective behaviors will be positively associated with students' satisfaction.

H3: Students' perception of college health professionals' communicative instrumental behavior will be positively associated with students' perceived quality of healthcare. H4: Students' perception of college health professionals' communicative affective behaviors will be positively associated with students' perceived quality of healthcare. As Bensing (1991) argues, patients are already anxious and uncertainty about their health problems before they see health professionals. Anxiety and uncertainty are likely to fluctuate depending on the outcomes of the interaction between patients and health professionals. For patients to be able to communicate effectively with health professionals, they need to manage their anxiety and uncertainty to a certain level that is neither above their maximum thresholds nor below their minimum thresholds. AUM theory, though an intercultural communication theory, provides useful explanation for how patients can manage their anxiety and uncertainty during medical encounters. Therefore, the current study will use AUM theory to explore these research questions:

RQ1: In what ways could students manage their anxiety when they interacted with college health professionals at student health services? 
RQ2: In what ways could students manage their uncertainty when they interacted with college health professionals at student health services? 


\section{CHAPTER III: METHODS}

\section{Participants}

Participants for the study were students from a large Midwestern University. The criteria for participation included that students be at least 18 years old, be current students at the university, and had visited the student health services center on campus. Participants were recruited through School of Communication research pool. Extra credit was offered to participants. There were various completions of the online survey. While 195 participants completed the instruments measuring the association between college health professionals' communicative behaviors, students' satisfaction, and perceived quality of healthcare, 184 participants completed the open-ended questionnaires on anxiety and uncertainty management. The reason attributable to the difference in completion was that the closed-ended instruments appeared first on the online survey.

\section{Demographics}

Of the 184 completed responses, 132 participants were females representing $71.74 \%, 50$ were males respresnting $27.17 \%$, one transgender representing $0.54 \%$, and one preferred not to disclsose his or her gender identity representing $0.5 \%$. The age of participants ranged from 19 to 25 years. While 165 participants were USA citizens reperesnting 89.67\%, 19 were interantional students represnting $10.33 \%$. In terms of participants' years in college, 45 were freshman representing 24.46\%, 17 sophomores representing 9.24\%, 51 juniors representing $27.72 \%, 39$ seniors representing $21.20 \%, 30$ graduate students representing $16.30 \%$, and two participants decided not to disclose their school year representing $1.1 \%$. 


\section{Data Collection}

An online survey, which contained both open-ended questionnaires and multiple-item scales, was distributed to participants via a departmental research pool. While the open-ended questionnaires collected data on how students managed their anxiety and uncertainty, the measuring item scales collected data on college health professionals' communicative behaviors (instrumental and affective), students' satisfaction and students' perceived quality of healthcare. The open-ended questionnaires were utilized because they allowed participants to use their own words to freely express how they managed their anxiety and uncertainty without any suggestive influence from the researcher (Foddy, 1993). The measuring instruments adopted both Likert and bi-polar scales. The survey took approximately 20 to 30 minutes to complete, and the participants' responses were anonymous because they could not place names and other identifiers on the survey.

\section{Procedures}

Before participants could proceed to the online survey, they confirmed that they had read the consent form. After answering 'yes' to a question about whether they had visited the student health service center on campus, participants proceeded to the survey to answer multiple items about health professionals' communicative instrumental and affective behaviors, their (participants') satisfaction and perceived quality of healthcare. Then, participants proceeded to answer the open-ended questionnaires about how they managed their anxiety and uncertainty. To complete the survey, participants answered basic questions about their demographics including gender, age, year of school, and residential status. 


\section{Variables and Measures}

The first part of this study used a correlational approach where participants filled out measures on instrumental and affective behaviors that were then correlated with measures on students' satisfaction and perceived quality of healthcare. The study variables included college health professionals' communicative instrumental behavior, college health professionals' communicative affective behavior, students' satisfaction, and students' perceived quality of healthcare. These variables including their measures were discussed below:

College health professionals' instrumental behavior. The Index of Understanding Scale adapted from Dyche and Swiderski's (2005) study was employed to measure this variable. The Scale contained eight items that required participants to rate how any health professional(s) provided information and answered questions about their health when they visited student health services on campus. Some of the items asked participants to indicate the degree to which "the health professional answered my questions" and "the health professional explained things in worlds I could understand" on a 5-point Likert scale ranging from always to never.

College health professionals' affective behavior. This variable was measured by using the Communicative Involvement Scale, adapted from Mataki's (2000) study. This scale contained ten items. These items on the survey required participants to rate the communicative involvement of college health professionals at the student health services. Some of these items asked participants to indicate the degree to which "the health professional listened carefully to me" and "the health professional was very observant during his or her conversation with me" on a 5-point Likert scale from strongly disagree to strongly agree. The Alpha reliability for this scale had been reported as .81 (Cegala, Savage, Brunner, \& Conrad, 1982). 
Students' satisfaction. The Medical Communication Competence Scale adopted from Cegala, Coleman, and Turner (1998) measured this variable. The scale contained 23 items that required participants to rate their satisfaction with college health professionals' communication competence. Some of the items asked participants to gauge their level of agreement with statements that "the health professional explained what my medical problem was to my satisfaction" and "the health professional did a good job reviewing or repeating important information" on a 7-point Likert scale ranging from strongly agree to disagree. The Alpha reliability for this measuring instrument ranged from .83 to .87 .

Students' perceived quality of healthcare. The Perceived Quality of Medical Care Scale adopted from Richmond, Smith, Heisel, and McCroskey (2013) was used to measure this variable. The scale contained six items that required participants to rate the quality of healthcare they received at student health services on campus. Items asked participants to rate the overall quality of their healthcare on dimensions such as "High Quality and Low Quality" and "Caring and Uncaring" on a 7-point bipolar scale, where the middle score (4) indicates a participant is undecided. This measuring scale had an Alpha reliability above .90 .

\section{Open-Ended Questions}

The second part of this study utilized open-ended questions to collect data on how students managed their anxiety and uncertainty when they interacted with college health professionals at student health services on a university campus. Participants were asked to answer four questions. Two questions related to $R Q 1$, managing anxiety. These included, "In what ways were you anxious when you interacted with college health professionals at student health services?" and "How did you deal with your anxiousness?" The remaining two questions were related to $R Q 2$, managing uncertainty. These were, "In what ways were you not sure about 
your health when you interacted with college health professionals at student health services?" and "How did you deal with your uncertainty"

\section{Data Analysis}

This study utilized both qualitative and quantitative methods to analyze two set of data. With the help of Statistical Package for the Social Sciences (SPSS), Pearson product-moment correlations were conducted to analyze the associations between college health professionals' communicative behaviors (instrumental and affective), students' satisfaction, and students' perceived quality of healthcare. Additionally, for the qualitative data, a thematic constant comparative method was used to analyze how students managed their anxiety and uncertainty when they interacted with college health professionals at student health services (Glaser \& Strauss, 1967).

To carry out this thematic analysis, Strauss and Corbin's (1998) open coding procedure was utilized to "open up the text and expose the thoughts, ideas, and meanings contained" in the data (p. 102). This procedure enabled me to identify concepts within the data. I compared these identified concepts for similarities and differences. I then grouped the concepts with similar meanings together and gave them a common name to differentiate one category from another (Strauss \& Corbin, 1998). To boost the credibility of the results of the qualitative data, I archived one fourth (46 responses) of the data, meaning that the archived data was excluded in the final analysis. After reaching tentative results, I used the archived data to perform "referential adequacy" test on them (Lincoln \& Guba, 1985, p. 13). The archived data supported the conclusions from the original analysis, suggesting that I had achieved saturation because no new findings appeared in the archived data. 


\section{CHAPTER IV: RESULTS FOR QUANTITATIVE DATA}

A series of Pearson product-moment correlations were performed by using SPSS to analyze the associations between college health professionals' communicative behaviors (instrumental and affective), students' satisfaction, and students' perceived quality of healthcare. The data supported all the four hypotheses.

Hypothesis one, $H 1$, tested for an association between college health professionals' communicative instrumental behavior and students' satisfaction. The computational analysis showed a statistically significant association between the two variables, $r(190)=.81, p<.001$, which is considered a strong positive association.

Hypothesis two, $\mathrm{H} 2$, tested for an association between college health professionals' communicative affective behavior and students' satisfaction. The computational analysis showed a statistically significant association between the two variables, $r(190)=.80, p<.001$, which is considered a strong positive association.

Hypothesis three, H3, tested for an association between college health professionals' communicative instrumental behavior and students' perceived quality of healthcare. The computational analysis showed a statistically significant association between the two variables, $r(189)=.67, p<.001$, which is considered a moderate positive association.

Finally, hypothesis four, $H 4$, tested for an association between college health professionals' communicative affective behavior and students' perceived quality of healthcare. The computational analysis showed a statistically significant association between the two variables, $r(189)=.60, p<.001$, which is considered a moderate positive association. 


\section{Discussion of Quantitative Results}

\section{Summary of Findings}

This study sought to analyze the associations between college health professionals' communicative behaviors (instrumental and affective), students' satisfaction, and students' perceived quality of healthcare. The results showed that the data supported all four hypotheses, meaning that there were statistically significant associations between health professionals' communicative behaviors, students' satisfaction, and students' perceived quality of healthcare.

Specifically, college health professionals' communicative instrumental and affective behaviors had strong positive associations with students' satisfaction. The implication is that as college health professionals' instrumental or affective behavior increases, students' satisfaction with healthcare services delivered at student health service also increases. Inversely, students' satisfaction decreases as college health professionals' instrumental or affective behavior decreases. These results are consistent with studies of Bensing and Dronkers (1992) and Ranjbaran et al. (2012) which found instrumental or informational behaviors (giving information, counseling, questioning) to be positively associated with patient satisfaction. The results are also in congruent with studies of Roberts and Aruguete (2000) and Robinson and Heritage (2006) which found a positive significant relationship between affective behaviors and patient satisfaction. Particularly, Roberts and Aruguete (2000) found that patients were more satisfied and trusting when physicians showed high affective (socio-emotional) behaviors than when they showed low affective behaviors. This suggests that college health professionals need to pay careful attention to how they communicate with student patients to avoid miscommunication, which is likely to cause low satisfaction among students seeking for healthcare at student health services. For instance, Ranjbaran et al. (2000) articulate that 
physicians' affective behaviors support patients' needs such as medical treatment and the desire to be relieved from stress.

Additionally, previous research (Koemer \& Kilbane, 2008; Moore et al., 2009; \& Uitterhoeve et al., 2009) conducted in traditional healthcare settings (off-campus) found that affective behavior had a stronger association with patient satisfaction than instrumental behavior. The present finding however contradicts the previous finding because both instrumental and affective behaviors were strongly related to patient satisfaction. The possible explanation for this contradiction may be that college students have some health needs that are different from those of traditional patients. The difference in health needs may cause students to have different expectations about health professionals' communicative behaviors. Age difference may also be a possible explanation for this contradiction since college students are relatively younger than patients in traditional health centers (American College Health Association, 2016). Notably, Moore et al. (2009) suggest that patients may not be educated enough to be able to evaluate physicians' technical (instrumental) behavior, leading affective behavior to have the stronger association with patient satisfaction. But the present results imply that college students might be getting enough education to evaluate health professionals' technical behaviors since both instrumental and affective behaviors had strong associations with patient satisfaction. It can also be inferred that students might be reading more about health professionals and their various competences through student health service' website or other online sources.

Moreover, the results showed that the associations between college health professionals' instrumental and affective behaviors and students' perceived quality of healthcare were moderately positive. While the positive association between instrumental behavior and students' perceived quality of healthcare supports previous research, the moderately positive association 
between affective behavior and students' perceived quality of healthcare disagrees with previous research where the association was strongly positive (Bensing, 1991; Bensing \& Dronker, 1992). The present results further contradict literature that affective behavior had stronger association with perceived quality of healthcare because both affective and instrumental behaviors had moderate associations with perceived quality of healthcare. This implies that students might perceive no difference between the importance of affective and instrumental behaviors in their evaluations of medical services. Hence, college health professionals' instrumental and affective behaviors are moderately associated with students' perceived quality of healthcare delivered at student health services.

\section{Strengths, Limitations, and Future Research of Quantitative Results}

The findings of this study provide practical implication for college health professionals to consider the potential impact of their communication on student patients' satisfaction and perceived quality of healthcare at student health services. As a result, the present findings should inform student health service the need to develop communication skills training programs for college health professionals to improve and update their communication skills. The content of the training program should focus on how to give information, ask questions, counsel, listen, empathize, reassure, and legitimize feelings of student patients. Because this study looked at students' perception of college health professionals' communicative behaviors, future research could utilize ethnographic approach to observe actual interactions between college health professionals and students at student health services. This will allow the researcher to have a first-hand examination of the communicative skill sets of college health professionals. This way, the researcher could determine which communicative skills should be included in the content of 
training programs to be designed for health professionals working at student health services on college and university campuses.

As a methodological strength to this study, the findings can be generalized to the entire student population of the studied university because public speaking students representing all majors at the university were recruited through a communication department research pool as participants for this study. However, the findings cannot be generalized to all college students across US. Thus, future research could expand the sample to include students from other colleges and universities to make findings more generalizable to college and university students.

Expanding the sample would also determine whether any future findings would be similar to or different from the present findings.

Additionally, the present study only assessed the association between college health professionals' communicative behaviors, students' satisfaction, and students' perceived quality of healthcare, meaning that any causal effect could not be established. Future research should assess the causal effect of college health professionals' communicative behaviors on students' satisfaction and perceived quality of healthcare at student health service. Moreover, the current findings could not offer explanation into why college health professionals' communicative behaviors were significantly positively associated with students' satisfaction and perceived quality of healthcare. Future researchers should conduct interviews and focus group discussions to enhance our understanding of why there were significant positives associations among the studied variables.

Lastly, future research should investigate whether the gender or age of college health professionals could play a role in their communication with students who accessed healthcare at student health service and the impact of their communication on students' satisfaction and 
perceived quality of healthcare. Specifically, gender will be relevant to study given the important role gender identity and individuals' preferred pronounce play in interactional or interpersonal situations (Kuvalanka, Weiner, Munroe, Goldberg, \& Gardner, 2017; \& Wagner, Kunkel, \& Compton, 2016). Other future scholarship could also examine whether international students and American students would have similar or different satisfaction and perception of quality of healthcare in relations to college health professionals' communicative behaviors, as previous research documents that immigrant patients may be reluctant and fearful when speaking with physicians due to their limited language proficiency and cultural differences (Ahmed, Lee, Shommu, Rumana, \& Turin, 2017).

\section{Conclusion}

The findings of this study show that students' perceptions of college health professionals' communicative behaviors were positively associated with students' satisfaction and students' perceived quality of healthcare delivery. This implies that as students perceive college health professionals' communicative behavior to be high, their perception of satisfaction and quality of healthcare delivery will also be high, indicating that any perceived miscommunication between college health professionals and student can lead students to perceive low satisfaction and quality of healthcare delivery at student health service. Therefore, college health professionals should give much importance to how they communicate with student patients at student health service on college or university campuses. Future researchers should use ethnographic approach to observe actual interactions between college health professionals and students to design communication skills training programs which are more specific to and appropriate for health professionals working at student health service centers on college and university campuses. 


\section{CHAPTER V: RESULTS FOR QUALITATIVE DATA}

The analysis showed that many participants indicated they were anxious and uncertain during their interactions with college health professionals at the student health service on campus. Interestingly, while some of their responses suggested they were anxious and uncertain before their interactions with college health professionals, other responses suggested participants were anxious and uncertain during their actual interactions. Trust, relaxation, and information seeking/giving were the broad themes identified as main strategies participants reported using to manage both their anxiety and uncertainty when seeking health services at student health service, suggesting that anxiety and uncertainty are inextricably related to each other. This is consistent with Bensing's (1991) argument that both uncertainty and anxiety problems are interrelated. These broad themes have sub-themes: trust (call a personal doctor and reassurance), relaxation (stay calm and positive), and information seeking/giving (ask questions, provide information, and conduct research).

\section{Trust}

This theme was identified in participants' responses as a strategy in managing their anxiety and uncertainty. To better capture participants' responses, trust was sub-categorized into reassurance and call a personal doctor.

\section{Reassurance}

Some participants assured themselves that they would get better without giving any particular reasons: "Told myself that I was going to get better", "I usually just tell myself that I'll be okay, and I'll feel better after I get medicine", etc. These types of responses were more prominent in participants' responses about how they managed their uncertainty. Other participants told themselves to trust the health professionals because they were competent in 
their job: "I remembered they were doctors and if I was sick they would catch it", "Just let the [health] professionals do their job", "Having some faith and trust that the doctors would diagnose the ailment correctly", "I dealt with my uncertainty by trusting the healthcare professional because she seemed to know what she was doing despite being a little confused on how to treat me", etc. The last response implies that there was a moment where the participant had a shred of doubt about the health professional's competence. These types of responses were present in both answers to anxiety and uncertainty management. Moreover, these responses suggest that participants were anxious and uncertain about their health issues and dealt with those health issues before their interactions with college health professionals at student health services. Other participants said that they could manage their anxiety and uncertainty because of assurances from the college health professionals that they (participants) would get better: "My uncertainty was dealt with by their reassurance", "They [health professionals] assured me that everything was private and that they would need full information to prescribe and/or diagnose me". The latter response suggests that patients, particularly students, will trust health professionals when

they are explicitly assured of confidentiality. It further suggests a co-management of participants' anxiety and uncertainty.

\section{Call a Personal Doctor}

This sub-theme indicates that some participants did not to some extent trust college health professionals and had to call their personal doctors as a strategy to deal with their uncertainty. These participants called their personal doctors after their encounters with college health professionals, implying that their interactions with health professionals could not help them to deal with their uncertainty. And to deal with their uncertainty, participants resorted to calling their personal doctors: "When I do go visit there, I will just call my primary care doctor 
after I visit with the [college] health professionals", "I followed up with actual health care provider and received the care I needed", etc. Another response highlighted the extent of trust participants had in college health professionals:

I do believe what they told me is true and that what I had is something that can be solved with something as small as ibuprofen. But at the same time whenever I have health concerns. I'm never truly satisfied with just talking to the [student] health services here. I always have the want to speak to my doctor from home. I have much trust in them than I do here.

These responses suggest that college students perceive health professionals in traditional health setting as more competent than those at student health service, though research shows that college health professionals are equally competent.

\section{Information Seeking/Giving}

Some participants resorted to seeking or giving information as their strategy to manage their anxiety and uncertainty. This strategy varies among participants as some relied on asking questions; others resorted to conducting research; and another group provided more information. These varied strategies were then sub-categorized under information seeking/giving theme to capture accurately the nuances in participants' responses.

\section{Ask Questions}

Asking questions was the most common strategy identified in participants' responses in dealing with their anxiety and uncertainty. Because they were anxious and uncertain about their health problems, some participants mentioned that they made sure to ask a lot of questions before leaving: "I made sure to keep asking questions and made sure I had answers before leaving", "I was able to ask questions and she answered them and explained what each thing meant as we 
went along", "Asked them a bunch of questions even if it was a simple and straightforward question". These responses suggest that participants left student health service with minimal or no anxiety and uncertainty because they appeared to be satisfied with answers to their questions. A particular respondent reported that he or she specifically asked health professionals questions to ascertain the source of his or her uncertainty: "Ask questions and try to figure out where the uncertainty is coming from".

\section{Conduct Research}

As a strategy to manage their anxiety and uncertainty, some participants researched for more information about their health problems online before meeting college health professionals: "I did research online and listed all of my symptoms as thoroughly as possible to the doctor", "I googled my side-effects to see if they were normal", "I did my own research and tried to ask questions", etc. A respondent resorted to getting more information from the website of student health service before going for his or her appointment: "I dealt with my anxiety by reading a lot about the student health services center on the website, so I felt informed and ready for my appointment”. These responses suggest that conducting research for information about either their health problems or the student health service might have informed them to ask a lot of questions during their interactions with college health professionals. Additionally, the responses suggest that some students were either uncertain about their health condition or the treatment they would receive from student health services.

\section{Provide Information}

Some participants said that providing detailed and clear information about their health concerns was a strategy used to manage their anxiety and uncertainty: "I explained the pain as best as I could”, “I thoroughly explained all my symptoms and did online research", "I made 
sure to give all information I had on my health, and took my time answering questions to make sure I was confident in my answers", "I gave them information on what was happening and then further explained what sickness I had", etc. Other responses indicate participants repeating themselves and answering any questions college health professionals might have about their concern to avoid possible misunderstandings: "I tried to talk and repeat the same thing in order to make sure the doctor understand what I meant", "Answering questions and being more detailed with my health issue", "I tried to talk clearly and at times to speak like Americans do even though I am an international student", etc. The last response highlights efforts of participants to ensure that they were clearly understood. Their responses further suggest that their anxiety and uncertainty declined when they felt being understood.

\section{Relaxation}

Most participants responded using some relaxation techniques as a strategy to deal with their anxiety and uncertainty. They employed these relaxation techniques to stay calm and positive. As a result, the relaxation theme was sub-categorized into stay calm and stay positive.

\section{Stay Calm}

Taking a deep breath, listening to music, and working out more were the most common relaxing techniques some participants used to calm down as their anxiety and uncertainty management strategy. These techniques were used prior to their interactions with college health

professionals. Examples of such responses included "If I get nervous I take deep breaths", "I just relaxed and listened to music with my headphones and trusted they would help me", "I tried to find a breathing pattern that would calm me down", "I work out a lot and hung out with friends", etc. Interestingly, one participant's response seems to confirm the notion that anxiety and uncertainty are inextricably related: "I usually just get quiet when I am uncertain about 
something because [when] I get nervous they will think that I am dumb". Other responses suggest that talking to friends, family (particularly, mothers), and a professor helped some participants to deal with their anxiety and uncertainty prior to their appointments with college health professionals: "I told my mom", "Texting a friend or parent", "Spoke with my brothers and parents, who gave me confidence", "I talked to my professor and went to student health services, I also talked to my parents and friends", etc. These responses were more prominent in participants' answers to dealing with anxiety than uncertainty.

\section{Stay Positive}

As a strategy to deal with their anxiety and uncertainty, some participants said they needed to stay positive by focusing on things they enjoyed and avoiding negative thoughts or things: "Began to partake in thing that I enjoy", "I tried not to think of the possibility of getting sick and having to miss school", "positive thinking", "I made sure to ignore them [college health professionals] being rude to me and get my diagnoses", etc. These responses suggest that participants used staying positive strategy during their interactions with college health professionals.

\section{Discussion of Qualitative Results}

\section{Summary of Findings}

Babrow and Mattson (2011) argue that most health communication scholarship is not theory driven to emphasize the great importance of using theories to inform research in this postmodern era. Bensing (1991) also articulates that patients are already uncertainty and anxious about their health problems even before they meet their doctors. Anxiety and uncertainty are likely to fluctuate depending on outcomes of interactions between patients and their doctors. For example, Ranjbarian et al. (2012) found that instrumental or informational aspects of physician 
patient communication could cause some anxiety relief for patients. Such outcomes of their interactions can possibly impact their general health outcomes such as satisfaction and quality of healthcare delivery, emphasizing the need for patients to manage their anxiety and uncertainty during any medical encounters. Thus, this study sought to utilize anxiety/uncertainty management (AUM) theory, though an intercultural theory which is hardly applied in health communication, particularly patient-doctor communication, to explore how college students managed their anxiety and uncertainty when they interacted with health professionals at student health services.

First, interpreting these findings in light of AUM theory, this study found that many students indicated that they were anxious and uncertain about their health problems when they sought healthcare delivery at student health service. Importantly, most students suggested they were able to manage their anxiety and uncertainty about their health problems using several strategies. According to AUM theory, when a person is able to manage his or her anxiety and uncertainty levels within their minimum and maximum thresholds, he or she can communicate effectively to strangers (Gudykunst, 2005). This assumption suggests that most students communicated effectively with college health professionals since they (students) reported their ability to manage their anxiety and uncertainty within the minimum and maximum thresholds. AUM theory posits that if an individual's anxiety and uncertainty are within their minimum and maximum thresholds, they are confident in predicting accurately the communicative behaviors of strangers. Because students reported they were able to manage their anxiety and uncertainty, they might have the confidence to accurately predict college health professionals' communicative behaviors. Additionally, the findings seemed to suggest that anxiety and uncertainty are inextricably related as some students reported that their anxiety was as result of their lack of 
enough information about their health problems. This finding is consistent with Bensing's (1991) suggestion that both uncertainty and anxiety problems are interrelated.

Second, the findings showed that most students said that they trusted college health professionals as a strategy to deal with their anxiety and uncertainty. Some students reported reassuring themselves that they would get better because the college health professionals knew what to do, suggesting that the college health professionals are competent in their job. Gudykunst (2005) indicates that trust and fear affect the level of anxiety one experiences when communicating with strangers. While trust induces positive outcomes such as understanding from any communication episodes with strangers, fear causes negative outcomes such as misunderstanding (Gudykunst, 2005). Per this logic, it is right to suggest that students understood the college health professionals during their interactions because the former trusted the latter. However, a few students reported calling their personal doctors after their encounters with the college health professionals to deal with their uncertainty. This implies their lack of trust in the college health professionals as one participant reported, "I followed up with actual health care provider and received the care I needed". Lack of trust tends to breed fear. Fear might have caused students to misunderstand the college health professionals, hence justifying the need to call their personal doctors.

Additionally, the present findings revealed that some students reported using relaxation techniques such as taking deep breaths, listening to music, and working out more to manage their anxiety. Simonds, Hunt, and Simonds (2018) refer to these relaxation strategies as systematic desensitization, which is useful in dealing with physical symptoms of communication apprehension. This implies that these students manifested physical symptoms of anxiety before their interaction with the college health professionals and had to resort to systematic 
desensitization to manage those symptoms. The findings further showed that other students chose to focus their minds on the positive things rather than the negatives during their interactions with the college health professionals. Simonds et al. refer to this strategy as cognitive restructuring, which is useful in managing psychological symptoms of communication anxiety. This suggests that some students used cognitive restructuring techniques to manage their psychological symptoms of anxiety when they interacted with the college health professionals at student health services.

Lastly, this study found that, as a strategy to deal with their anxiety and uncertainty, some students reported searching for more information online about their health problems or student health service on its website before going for their appointments at the campus health center. This finding contradicts that of Hammer et al.'s (1988) study that information gathering strategies had no relationship with uncertainty and anxiety because information gathering strategies enhanced "the development of interpersonal and intergroup saliencies rather than influencing uncertainty and anxiety reduction" (p. 323). This contradiction in information strategy may be due to the Internet making health information easily available and accessible online. Conducting research for more information about their health problems or student health service might have informed students to ask a lot of questions during their interactions with the college health professionals as indicated in the findings of this study. This suggests that students had some level of knowledge about their health issues or student health service when they interacted with college health professionals. Corroborating the present findings, Whitaker (2013) found that respondents perceived that their knowledge about how strangers would react enabled them to reduce their anxiety, which ensured effective communication with strangers. The findings suggest that, because they had some level of knowledge about student health services, 
students might have communicated effectively with the college health professionals. AUM theory also contends that having enough information about strangers enabled a person to accurately predict communicative behaviors of those strangers. This suggests that since students reported gathering information about student health service, they might be able to accurately predict communicative behaviors of college health professionals. The findings further showed that other students made sure to provide clear and detailed information about their health problems to the college health professionals. According to some students, this helped them to manage any anxiety and uncertainty they had about their health problems.

\section{Strengths, Limitations, and Future Research of Qualitative Results}

One strength of these findings is that they provide practical and easy to use strategies student patients can apply to manage their anxiety and uncertainty about their health problems before and during their medical appointments. Future health communication scholars and professionals working in the health promotion and wellness department of higher educational institutions could use the findings of this study to develop training manuals and educational materials to train and educate students on some strategies they could use to manage their anxiety and uncertainty about their health issues when going for medical appointments at student health services on college and university campuses.

Additionally, the use of an online survey as the data collection instrument afforded participants anonymity and allowed them ample time to respond to the survey at their own convenience. More so, the open-ended questionnaire allowed participants to freely express themselves about how they could manage their anxiety and uncertainty during their interactions with college health professionals without any suggestive influence from the researcher (Foddy, 1993). However, the survey did not allow an in-depth analysis because responses participants 
provided were mostly short and scanty, and it was sometimes difficult to get the sense of what participants were saying. Future research which intends to replicate this study should utilize interviews and focus group discussions to gather richer, thicker, and more in-depth data about participants' experiences of how they managed their anxiety and uncertainty about their health issues. Also, interviews and focus group discussions allow for asking follow-up questions for more clarifications (Lindlof \& Taylor, 2011).

Though a majority of participants were public speaking students representing all majors at the university, they were most likely familiar and knowledgeable about communication apprehension which is taught in the basic communication course required for all undergraduate students. This knowledge might potentially skew the findings. Future research should broaden the sample to include graduate students from all departments who are not required to take the basic communication course as participants to compare future findings with the current for any similarities and differences. The sample should also be expanded to other institutions to make the findings more generalizable to all college and university students. This exploratory study could guide future research interested in designing and developing measuring instruments for AUM theory that are more specific to patient-doctor communication to accurately assess the relationship between patients' anxiety and uncertainty management and health providers' communicative behaviors or the effects of health providers' communicative behaviors on patients' anxiety and uncertainty management during medical interactions. This type of study would help determine which aspect of health professionals' communicative behaviors would correlate with or impact patients' anxiety and uncertainty management as this was lacking in the present study. Again, the designed instrument or measuring scale would enable researchers to investigate the extent to which uncertainty and anxiety could mediate the relationship between 
health professionals' communicative behaviors and patient satisfaction and perceived quality of healthcare delivery.

\section{Conclusion}

This study responded to Babrow and Mattson's (2011) call that more health communication scholarship should be theory-driven by using anxiety/uncertainty management (AUM) theory to explore how college students managed their anxiety and uncertainty during their medical encounters with college health professionals at student health service. Though AUM theory is an intercultural and cross-cultural theory, which is hardly applied in health communication, this study has demonstrated its usefulness in contributing to our understanding of how students reported using trust, relaxation, and information seeking or giving as strategies to manage their anxiety and uncertainty about their health problems before and during their interactions with college health professionals. As AUM theory posits, students might communicate effectively with college health professionals since the former reported their ability to manage their anxiety and uncertainty within their minimum and maximum thresholds. Future health communication scholars and professionals working in health promotion and wellness departments of higher educational institutions could use the present findings to develop training manuals and educational materials to train and educate students on strategies they could use to manage their anxiety and uncertainty about their health problems before and during their medical appointments on campus health centers. 


\section{CHAPTER VI: GENERAL DISCUSSION}

This one study used both quantitative and qualitative methods to collect and analyze two sets of different data leading to different results. The quantitative method helped to test the relationship between college health professionals' communicative behaviors, student satisfaction, and students' perceived quality of healthcare delivery. The qualitative method assisted in answering how college students were able to manage their anxiety and uncertainty when they interacted with college health professionals at student health service. Initially, the researcher intended to find a measuring instruments for anxiety/uncertainty management (AUM) theory to examine how students' ability to manage their uncertainty and anxiety could mediate the relationship between college health professionals' communicative behaviors, student satisfaction, and students' perceived quality of healthcare. However, instruments that were found were not specific to and appropriate for this purpose. Therefore, the purpose was modified to ask qualitative research questions to understand participants' experiences of how they managed their anxiety and uncertainty.

\section{Summary of Findings}

This study sought to assess the associations between college health professionals' communicative behaviors (instrumental and affective), students' satisfaction, and students' perceived quality of healthcare. The results showed that the data supported all the four hypotheses, indicating that there were statistically significant positive associations between college health professionals' communicative behaviors, students' satisfaction, and students' perceived quality of healthcare. Both instrumental and affective behaviors had strong positive associations with students' satisfaction, contrasting previous research that affective behavior had stronger association with patient satisfaction than instrumental behavior (Koemer \& Kilbane, 
2008; Moore et al., 2009; Uitterhoeve et al., 2009). In fact, Moore et al. (2009) in their interpretation suggest that affective behavior had stronger association because patients were not educated enough to able to evaluate physicians' instrumental behaviors. However, the present findings suggest that students could evaluate instrumental behaviors of college health professionals. Again, this study found that both instrumental and affective behaviors moderately associated with students' perceived quality of healthcare, contradicting previous research that affective behavior had stronger association with patients' perceived quality of healthcare (Bensing, 1991; \& Bensing \& Dronker, 1992). The implication of the present findings is that college health professionals need to pay careful attention to how they should communicate with students to avoid miscommunication, which is likely to cause low satisfaction and perceived quality of healthcare among students who access student health service on a university campus.

Moreover, previous research shows that patients are already anxious and uncertain about their health problem before meeting their doctors, and their anxiety and uncertain are likely to change depending on the outcomes of their interactions (Bensing, 1991). Therefore, this study also utilized anxiety/uncertainty management (AUM) theory to explore and understand how student managed their anxiety and uncertainty during their interactions with college health professionals at student health service. The findings indicated that many students reported using trust, relaxation, and information seeking/giving as strategies to manage their anxiety and uncertainty about their health problems before and during their interactions with college health professionals. AUM theory posits that an individual who can manage his or her anxiety and uncertainty within the minimum and maximum thresholds can communicate effectively with stranger Gudykunst, 2005). This suggests that the management of uncertainty or anxiety might have helped students to have effective interactions with college health professionals at student 
health service. This study also found that students used systematic desensitization and cognitive restructuring as strategies to deal with their physical and psychological symptoms of anxiety respectively (Simonds et al., 2018). According to AUM theory, since students reported gathering information about college health professionals, they might be able to accurately predict college health professionals' communicative behaviors.

\section{Synthesis of Quantitative and Qualitative Findings}

The quantitative findings, in contrasting previous researchers' interpretations of their results that patients were not educated enough to evaluate instrumental behavior of physicians, suggest that students had enough education and information because they could evaluate instrumental behaviors of college health professionals. Also, the qualitative data found that students gathered more information about their health problems online and student health service on its website before going for their appointments. This could be offered as a possible explanation into why students might be able to evaluate college health professionals' instrumental behaviors since both instrumental and affective behaviors were positively associated with students' satisfaction and perceived quality of healthcare.

\section{Strengths, Limitations, and Future Research}

The findings of this thesis provide practical implications for college health professionals to consider how they communicate with students because their interactions can potentially cause high or low patient satisfaction and perceived quality of healthcare among students seeking for health services at student health service. Health communication trainers could use these findings to develop training manuals (focusing on effective ways to ask and answer questions, give information, counsel, and empathize with student patients) to help college health professionals improve their communication skills. Future researchers should use ethnographic approach to 
observe interactions between college health professionals and student to design communication skills training programs which are more specific to and appropriate for health professionals working at student health service. Again, the thesis' findings provide practical strategies such as trust, relaxation, information seeking/giving students can use to manage their anxiety and uncertainty during any medical encounters at student health service. Future scholars and professionals working at health promotion and wellness departments of educational institutions could use present findings to develop training and educational manuals to train and educate students about some health-related anxiety and uncertainty management strategies.

Additionally, the present findings could not be generalized to all college and university students. Future research examining this phenomenon should expand the sample to include other universities to make future findings more generalizable. Expanding the sample could help to determine whether the current conclusions would apply to a broader student population. Furthermore, this thesis could not provide an explanation into why both instrumental and affective behaviors positively associated with students' satisfaction and perceived quality of healthcare. Future scholarship should utilize interviews and focus group discussions to investigate why there were positive associations between college health professionals' communicative behaviors, students' satisfaction, and perceived satisfaction. Finally, this thesis only assessed associations between the studied variables; therefore, any causal effects could not be established. Future research could examine the causal effects of college health professionals' communicative behaviors on students' satisfaction and perceived quality of healthcare.

\section{Conclusions}

The present thesis found that students' perception of college health professionals' communicative behaviors was positively associated with students' satisfaction and students' 
perceived quality of healthcare. Therefore, college health professionals need to pay careful attention to how they communicate with students at student health service because their interactions could potentially cause low or high satisfaction and perceived quality of healthcare delivery among college students. Also, this thesis found that students reported using trust, relaxation, and information seeking/giving as strategies to manage their anxiety and uncertainty about their health problems before and during their interactions with college health professionals at student health service. Though anxiety/uncertainty management (AUM) theory is an intercultural and cross-cultural theory, this study has demonstrated its utility or useful application in health communication scholarship to aid our understanding of how student patients managed their anxiety and uncertainty when they interacted with college health professionals. This thesis serves as foundational research on college health professionals and students communication at student health service centers on college and university campuses to inspire future health communication scholars to investigate this under-studied phenomenon of student health services. 


\section{REFERENCES}

Ahenkan, A., \& Adu-Adjei, K. (2017). Predictors of patient satisfaction with quality of healthcare in university hospitals in Ghana. Hospital Practices and Research, 2(1), 9-14. doi:10.1517/hpr.2017.03

Ahmed, S., Lee, S., Shommu, N., Rumana, N., \& Turin, T. (2017). Experiences of communication barriers between physicians and immigrant patients: A systematic review and thematic synthesis. Patient Experience Journal, 4(1), 122-140. Retrieved from https://pxjournal.org/cgi/viewcontent.cgi?article=1181\&context=journal

Ali, D. (2016). Patient satisfaction in dental healthcare centers. European Journal of Dentistry, 10, 309-314. doi:10.4103/1305-7456.184147

Alli, F., Maharaj, P., \& Vawda, M. Y. (2013). Interpersonal relations between health care workers and young clients: Barriers to accessing sexual and reproductive health care. Journal of Community Health, 38, 150-155. doi:10.1007/s10900-012-9595-3

Allred, N. J., Turner, J. C., David, F., DeLozier, D. M., \& Strikas, R. A. (2005). Responses of US college and university student health services to the 2004 influenza vaccine shortage. Journal of American College Health, 53(6), 291-294

Atinga, R. A., Abekah-Nkrumah, \& Domfeh, K. A. (2011). Managing healthcare quality in Ghana: A necessity of patient satisfaction. International Journal of Health Care Quality Assurance, 24(7), 548-563. doi:10.1108/0952686.11111.60580

American College Health Association. (2010). 2010 survey on the utilization of student health services. Hanover, MD: American College Health Association. Retrieved from https://www.acha.org/documents/resources/survey_data/benchmarking/ACHA_Benchma rking_Report_2010_Utilization_Survey.pdf 
American College Health Association. (2016). National college health assessment II:

Undergraduate student reference group executive summary spring 2016. Hanover, MD: American College Health Association. Retrieved from https://www.acha.org/documents/ncha/NCHAII_FALL_2016_UNDERGRADUATE_REFERENCE_GROUP_EXECUTIVE_SUMM ARY.pdf

Babrow, A. S., \& Mattson, M. (2011). Building health communication theories in the $21^{\text {st }}$ century. In T. L. Thompson, R. Parrot, \& J. F. Nussbaum (Eds.), The routledge handbook of health communication (pp. 18-35). New York, NY: Routledge

Badri, M. A., Attia, S., \& Ustadi, A. M. (2009). Healthcare quality and moderators of patient satisfaction: Testing for causality. International Journal of Health Care Quality Assurance, 22(4), 382-410. doi:10.1108/09526860910964843

Baldwin, D. R., Towler, K., Oliver, M. D., \& Datta, S. (2017). An examination of college student wellness: A research and liberal arts perspective. Health Psychology, 4(2), 1-9. doi:10.1177/2055102917719563

Bensing, J. (1991). Doctor-patient communication and the quality of care. Social Science \& Medicine, 32(11), 1301-1310. doi:10.1016/0277-9536(91)90047-G

Bensing, J. M., \& Dronker, J. (1992). Instrumental and affective aspects of physician behavior. Medical Care, 30(4), 283-298. doi:10.1097/00005650-1992040000-00001 
Bertakis, K. D., Roter, D., \& Putnam, S. M. (1991). The relationship of physician medical interview style to patient satisfaction. The Journal of Family Practice, 32(2), 175-181. Retrieved from https://www.researchgate.net/publication/21166056_The_Relationship_of_Physician_Me dical_Interview_Style_to_Patient_Satisfaction

Birch, S. J., \& Golbeck, A. L. (2015). The effectiveness of screening with interferon-gamma release assays in a university health care setting with a diverse global population. Journal of American College Health, 63(3), 180-185. doi:10.1080/07448481.2014.1003378

Campbell, T. A., Auerbach, S. M., \& Kiesler, D. J. (2007). Relationship of interpersonal behaviors and health-related control appraisals to patient satisfaction and compliance in a university health center. Journal of American College Health, 55(6), 333-340. doi:10.3200/JACH.55.6.333-340

Canel, C., \& Fletcher, E. A. A. (2001). An analysis of service quality at student health center. International Journal of Health Care Quality Assurance, 14(6), 260-267. doi:10.1108/095260110404220

Canel, C, \& Kadipasaoglu, S. (2002). An efficiency study for a student health center. International Journal of Health Care Quality Assurance, 15(4), 159-167. doi:10.1108/09526860210431823

Cegala, D. J., Coleman, M. T., \& Turner, J. W. (1998). The development and partial assessment of the medical communication competence scale. Health Communication, 10(3), 261288. doi:10.1207/s15327027hc1003_5 
Cegala, D. J., Savage, G. T., Brunner, C. C., \& Conrad, A. B. (1982). An elaboration of the meaning of interaction involvement: Toward the development of a theoretical concept. Communication Monographs, 49(4), 229-248. doi:10.1080/03637758209376087

Checton, M. G., Greene, K., Magsamen-Conrad, K., \& Ventis, M. K. (2012). Patients' and partners' perspectives of chronic illness and its management. Families, Systems, \& Health, 30(2), 114-129. doi:10.1037/a0028598

Cheng, H. (2004). Being ill in a foreign land: International students' perceptions of an experience with university health services. A Graduate Journal of Qualitative Communication Research, 3, 70-92

Chen, J. G., Zou, B., \& Shuster, J. (2017). Relationship between patient satisfaction and physician characteristics. Journal of Patient Experience, _, 1-8. doi: $10.1177 / 2374373514453$

Cousin, G., Mast, M. S., Roter, D. L., \& Hall, J. A. (2012). Concordance between physician communication style and patient attitudes predict patient satisfaction. Patient Education and Counseling, 87, 193-197. doi:10.1016/j.pec.2011.08.004

Du Pre, A. (2017). Communicating about health: Current issues and perspectives ( $5^{\text {th }}$ ed.). Oxford University Press

Dunsch, F., Evans, D. K., Macis, M., \& Wang, Q. (2018). Bias in patient satisfaction surveys: A threat to measuring healthcare quality. BMJ Glob Health, 3, 1-6. doi:10.1136/bmjh-2017000694

Dutta-Bergman, M. J. (2005). The relationship between health-orientation, provider-patient communication, and satisfaction: An individual-difference approach. Health Communication, 18(3), 291-303. doi:10.1207/s15327027hc1803_6 
Dyche, L., \& Swiderski, D. (2005). The effect of physician solicitation approaches on ability to identify patient concerns. Journal of General Internal Medicine, 20, 267-270. doi:10.1111/j.1525-1497.2005.40266.x

Evans, B. J., Stanley, R. O., \& Burrows, G. D. (2009). Communication skills training and patients' satisfaction. Health Communication, 4(2), 155-170. doi:10.1207/s15327027hc0402_5

Foddy, W. (1993). Constructing questions for interview and questionnaires: Theory and practice in social research. Cambridge: Cambridge University Press.

Garcia, C. M., Lechner, K. E., Frerich, E. A., Lust, K. A., \& Eisenberg, M. E. (2014). College students' preferences for health care providers when accessing sexual health resources. Public Health Nurse, 31(5), 387-394. doi:10.1111/phn.12121

Ghahramanian, A., Rezaei, T., Abdullah, F., Sheikhalipour, Z., \& Dianat, I. (2017). Quality of healthcare services and its relationship with patient safety culture and nurse-physician professional communication. Health Promotion Perspectives, 7(3), 168-174. doi:10.15171/hpp.2017.30

Grace, T. W. (1997). Health problems of college students. Journal of American College Health, 45(6), 243-251. doi:10.1080/07448481.1997.9936894

Gudykunst, W. B. (1988). Uncertainty and anxiety. In Y. Y. Kim \& W. B. Gudykunst (Eds.), Theories in intercultural communication (pp. 123-156). Newbury Park, CA: Sage

Gudykunst, W. B. (1995). Anxiety/uncertainty management (AUM) theory: Current status. In R. L. Wiseman (Ed.), Intercultural communication theory (pp. 8-58). Thousand Oaks: CA. Sage 
Gudykunst, W. B. (2005). An anxiety/uncertainty management (AUM) theory of effective communication. In W. B. Gudykunst (Ed.), Theorizing about intercultural communication (pp. 281-322). Thousand Oaks, CA: Sage. ISBN: 9780761927495

Hall, J. A., Roter, D. L., \& Katz, N. R. (1988). Meta-analysis of correlation of provider behavior in medical encounters. Medical Care, 26(7), 657-675. doi:10.1097/00005650198807000-00002

Halstead, V., Williams, J. R., Gattamorta, K., \& Gonzalez-Guarda, R. (2017). Sexual violence screening practices of student health centers located on universities in Florida. Journal of American College Health, 68(8), 548-557. doi:10.1080/07448481.2017.1351447

Hailey, B. J., Pargeon, K., \& Crawford, V. (2000). Can healthcare providers at university health clinics predict patient satisfaction? Journal of American College Health, 49(3), 111-117. doi:10.1080/07448480009596292

Hammer, M. R., Wiseman, R. L., Rasmussen, J. L., \& Bruschke, J. C. (1998). A test of anxiety/uncertainty management theory: The intercultural adoption context. Communication Quarterly, 46(3), 309-326. doi:10.1080/01463379809370104

Hersh, D., Godecke, E., Armstrong, E., Ciccone, N., \& Bernhardt J. (2016). “Ward talk": Nurses' interaction with people with and without aphasia in the very early period poststroke. Aphasiology, 30(5), 609-628. doi:10.1080/02687038.2014.933520

Helitzer, D. L., LaNoue, Wilson, B., de Hernandez, B. U., Warner, T., \& Roter, D. (2011). A randomized controlled trial of communication training with primary care providers to improve patient-centeredness and health risk communication. Patient Education and Counseling, 82, 21-29. doi:10.1016/j.pec.2010.01.021 
Hooker, R. S., Potts, R., \& Ray, W. (1997). Patient satisfaction: Comparing physician assistants, nurse practitioners, and physicians. The Permeate Journal, 1(1), 38-42. Retrieved from https://www.researchgate.net/publication/233869056_Patient_Satisfaction_Comparing_P hysician_Assistants_Nurse_Practitioners_and_Physicians

Huy, N. V., Dung, N. N., Thang, C. D., \& Hanh, L. T. (2017). Patient satisfaction with health care services at a national institute of ophthalmology. International Journal of Health Planning Management, 33, 251-262. doi:10.1002/hpm.2449

Koemer, C. D., \& Kilbane, M. (2008). Physician sociality communication and its effect on patient's satisfaction. Communication Quarterly, 56(1), 69-86. doi:10.1080/01463370701839073

Kuvalanka, K. A., Weiner, J. L., Munroe, C., Goldberg, A. E., \& Gardner, M. (2017). Trans and gender-nonconforming children and their caregivers: Gender presentations, peer relations, and well-being at baseline. Journal of Family Psychology, 31(7), 889-899. doi:10.1037/famooo338

Lemly, D. C., Lawlor, K., Scherer, E. A., Kelemen, S., \& Weitzman, E. R. (2014). College health service capacity to support youth chronic medical conditions. Pediatrics, 134(5), 885-891. doi:10.15421peds.2014-1304

Lincoln, Y. S., \& Guba, E. G. (1985). Naturalistic inquiry. Newbury Park, CA: Sage.

Lindlof, T. R., \& Taylor, B. C. (2011). Qualitative communication research methods $\left(3^{\text {rd }}\right.$ ed.). Thousand Oaks: Sage. ISBN: 9781412974738

Mataki, S. (2000). Patient-dentist relationship. Journal of Medical Dentist Science, 47, 209-214. Retrieved from http://lib.tmd.ac.jp/jmd/4704/01_Mataki.pdf 
McMullen, M., \& Netland, P. A. (2013). Wait time as a driver of overall patient satisfaction in an ophthalmology clinic. Clinical Ophthalmology, 7, 1655-1660. doi:10.2147/OPTH.549382

Miller, A. N., \& Samp, J. A. (2007). Planning intercultural interaction: Extending anxiety/uncertainty management theory. Communication Research Reports, 24(2), 87-95. doi:10.1080/0882409071304717

Moore, S. D., Wright, K. B., \& Bernard, D. R. (2009). Influences on health delivery system satisfaction: A partial test of the ecological model. Health Communication, 24, 285-294. doi:10.1080/10410230902889225

Nelson, E. L., Miller, E. A., \& Larson, K. A. (2010). Reliability associated with the roter interaction analysis system (RIAS) adapted for the telemedicine context. Patient Education and Counseling, 78, 72-78. doi:10.016/j.pec.2009.04.003

Ni, L., \& Wang, Q. (2011). Anxiety and uncertainty management in an intercultural setting: The impact on organization-public relationships. Journal of Public Relations Research, 23(3), 269-301. doi:10.1080/1062726X.2011-582205

Ong, L. M. L., De Haes, J. C. J. M., Hoos, A. M., \& Lammes, F. B. (1995). Doctor-patient communication: A review of the literature. Social Science \& Medicine, 40(7), 903-918. doi:1016/0277-9536(94)00155-M

Perrault, E. K. (2018). Campus health centers' lack of information regarding providers: A content analysis of division-I campus health centers' provider websites. Health Communication, 33(7), 860-866. doi:10.1080/10410236.2017.1316635 
Ranjbarian, B., Emami, A., \& Ranjbarian, P. (2012). Dentists’ socio-emotional, informational behaviors and their patient's satisfaction: A case study from Iran. Middle-East Journal of Scientific Research, 11(3), 318-323. Retrieved from http://idosi.org/mejsr/mejsr11(3)12/9.pdf

Richmond, V. P., Smith, R. S., Heisel, A. M, \& McCroskey, J. C. (2013). Perceived quality of medical care (PQMC). Measurement instrument database for the social science. Retrieved from http://www.midss.ie

Roberts, C. A., \& Aruguette, M. S. (2000). Task and socio-emotional behaviors of physicians: A test of reciprocity and social interaction theories in analogue physician-patient encounters. Social Science \& Medicine, 50(3), 309-315. doi:10.10.1016/S02779536(99)00245-2

Robinson, J. D., \& Heritage, J. (2006). Physicians' opening questions and patients' satisfaction. Patient Education Counseling, 60(3), 279-285. doi:10.1016/j.pec.2005.11.009

Roter, D. L., \& Larson, S. (2001). The relationship between residents' and attending physicians' communication during primary care visits: An illustrative use of the roter interaction analysis system. Health Communication, 13(1), 33-48. doi:10.1207/S15327027HC1301_04

Roter, D. L., \& Larson, S. (2002). The roter interaction analysis system (RIAS): Utility and flexibility for analysis of medical interactions. Patient Education and Counseling, 46(4), 243-251. doi:10.1016/S0738-3991(02)00012-5

Rowland-Morin, P. A., \& Carroll, J. G. (1990). Verbal communication skills and patient satisfaction: A study of doctor-patient interviews. Education \& the Health Profession, 13(2), 168-185. doi:10.1177/016327879001300202 
Ruben, B. D. (2016). Communication theory and health communication practice: The more things change, the more they stay the same. Health Communication, 31, 1-11. doi:1080/10410236.2014.923086

Safaan, S. M., Elkhouly, E. A., \& Ibrahem, R. A. L. (2015). Collaboration among nurses and physicians and its relation to patient satisfaction. International Journal of Current Research, 7(3), 13299-13305. Retrieved from https://www.researchgate.net/publication/323430675_COLLABORATION_AMONG_N URSES_AND_PHYSICIANS_AND_ITS_RELATION_TO_PATIENT_SATISFACTIO $\mathrm{N}$

Sharma, V. (2017). Patient satisfaction and brand loyalty in health-care organizations in India. Journal of Asia Business Studies, 11(1), 73-87. doi:10.1108/JABS-09-2015-0157

Simonds, C. J., Hunt, S. K., \& Simonds, B. K. (2018). Engaging communication. Southlake, TX: Fountainhead Press.

Skorton, D., \& Altschuler, G. (2013). How college health centers help students succeed. Forbes. Retrieved from https://www.forbes.com/sites/collegeprose/2013/09/23/how-collegehealth-centers-help-students-succeed/\#97ff60d184b0

Sparks, L., Villagran, M. M., Parker-Raley, J., \& Cunningham, C. B. (2007). A patient-centered approach to breaking bad news: Communication guidelines for health care providers. Journal of Applied Communication Research, 35(2), 177-196.

doi:10.1080/00909880701262997

Spotts, P. H. (2017) Spontaneous pneumomediastinum: Case presentation to a college student health clinic. Journal of American College Health, 65(8), 575-578. doi:10.1080/07448481.2017.1350687 
Strauss, A., \& Corbin, J. (1998). Basics of qualitative research: Techniques and procedures for developing grounded theory ( $2^{\text {nd }}$ ed.). Thousand Oaks, CA: Sage Publication.

Thornton, B. C, \& Kreps, G. L. (1993). Perspectives on health communication. Prospect Heights, IL: Waveland Press, Inc.

Turner, J. C., \& Keller, A. (2015). College health surveillance network: Epidemiology and health care utilization of college students at US 4-year universities. Journal of American College Health, 63(8), 530-538. doi:10.1080/07448481.2015.1055567

Uiterhoeve, R., Bensing, J., Dilven, E., Donders, R., deMulder, P., \& Achterberg, T. V. (2009). Nurse-patient communication in cancer care: Does responding to patient's cues predict patient satisfaction with communication. Psycho-Oncology, 18, 1060-1068. doi:10.1002/pon.1434

van Servellen, G. V. (2009). Communication skills for health care professionals: Concepts, practice, and evidence ( $2^{\text {nd }}$ ed.). Sudbury, MA: Jones and Bartlett Publishers.

Verulava, T., Jorbenadze, R., Karimi, L., Dangadze, B., \& Barkalaia, T. (2018). Evaluation of patient satisfaction with cardiology services. The Open Public Health Journal, 11, 201208. doi:10.2174/1874944501811010201

Wagner, P. E., Kunkel, A., \& Compton, B. L. (2016). (Trans)lating identity: Exploring discursive strategies for navigating the tensions of identity gaps. Communication Quarterly, 64(3), 251-272. doi: 10.1080/01463373.2015.1103286

Wanzer, M. B., Booth-Butterfield, M., \& Gruber, K. (2004). Perceptions of health care providers' communication: Relationships between patient-centered communication and satisfaction. Health Communication, 16(3), 363-383. doi:10.1207/S15327027HC1603_6 
Whitaker, M. S. (2013). Anxiety/uncertainty management and its relationship to community as an anxiety management mechanism: A mixed methods, across case study of online graduate students (Doctoral dissertation). The University of Alabama, Tuscaloosa, Alabama

Wong, S. YS, \& Lee, A. (2006). Communication skills and doctor patient relationships. Medical Bulletin, 11(3), 7-9. Retrieved from http://www.fmshk.org/database/articles/607.pdf

Xesfingi, S., \& Vozikis, A. (2016). Patient satisfaction with the healthcare system: Assessing the impact of socioeconomic and healthcare provision factor. BMC Health Services Research, 16(94), 1-7. doi:10.1186/s1293-016.1327-4

Zakletskaia, L., Wilson, E., \& Fleming, M. F. (2010). Alcohol use in students seeking primary care treatment at university health services. Journal of American College Health, 59(3), 217-223. doi:10.1080/07448481.2010.502413 


\section{APPENDIX A: ONLINE SURVEY QUESTIONNAIRES}

\section{Open-Ended Questionnaires}

1. In your own words, how would you describe anxiety?

2. Based on your description, were you anxious when you first visited student health services on campus?

3. If you were anxious, could you describe how you were able to manage your anxiety?

4. Did your ability to manage your anxiety affect the way you interacted with health professionals at student health service? Please explain how.

5. In your own words, how would you describe uncertainty?

6. Based on your description, were you uncertain about your health when you first visited student health services on campus?

7. If you were uncertain about your health, could you describe how you were able to manage your uncertainty?

8. Did your ability to manage your uncertainty affect the way you interacted with health professionals at student health services? Please explain how.

\section{Measuring Items}

You will be provided series of statements about concerns any health professional(s) showed to you when you last visited the student health services on campus. Note that the health professional(s) include physician, physician assistant, nurse, nurse assistant, pharmacist, and lab attendant. Completion of these statements are voluntary. Please use the following scale: $1=$ always, $2=$ usually, $3=$ about half of the time, $4=$ occasionally, $5=$ never, to indicate the extent to which you agree with the following statements.

1. The health professional seemed interested in me as a person-----5 $\quad \begin{array}{llll}4 & 3 & 2 & 1\end{array}$ 
2. The health professional seemed in a hurry-----5 $\quad \begin{array}{lllll}4 & 3 & 2 & 1\end{array}$

3. The health professional was friendly and respectful-----5 $\quad \begin{array}{llll}4 & 3 & 2 & 1\end{array}$

4. The health professional answered my questions-----5 $\quad \begin{array}{lllll}4 & 3 & 2 & 1\end{array}$

5. The health professional(s) explained things in words I could understand-----5 $\quad 4 \quad 3 \quad \begin{array}{llll}4 & 2 & 1\end{array}$

6. The health professional(s) interrupted me-----5 $\quad \begin{array}{llll}4 & 3 & 2 & 1\end{array}$

7. The health professional(s) took as much time as needed-----5 $\quad \begin{array}{lllll}4 & 3 & 2 & 1\end{array}$

8. The health professional(s) helped me explain my concerns-----5 $\quad \begin{array}{llll}4 & 3 & 2 & 1\end{array}$

You will be provided series of statements about the communicative involvement of any health professional(s) when you last visited the student health services on campus. Note that the health professional(s) include physician, physician assistant, nurse, nurse assistant, pharmacist, and lab attendant. Completion of these statements are voluntary. Please use the following scale: $1=$ strongly disagree, $2=$ disagree, $3=$ undecided, $4=$ agree, $5=$ strongly agree, to indicate the extent to which you agree with the following statements.

1. The health professional listened carefully to me-----5 $4 \begin{array}{llll}4 & 2 & 1\end{array}$

2. The health professional was very observant during his or her conversation with me-----5 4 $\begin{array}{lll}3 & 2 & 1\end{array}$

3. The health professional was very responsive to what I said and what I needed-----5 $4 \quad 3 \quad 3$ 1

4. Often the health professional was unsure about how he or she was expected to respond-----5 $\begin{array}{llll}4 & 3 & 2 & 1\end{array}$

5. The health professional's mind seemed to wander, and he or she missed parts of what was going on-----5 $4 \quad 3 \quad 3 \quad 2 \quad 1$

6. The health professional did not know what I was really saying-----5 $\quad \begin{array}{llll}4 & 3 & 2 & 1\end{array}$ 
7. The health professional really knew what was going on; that is, he or she really had a handle of the situation-----5 $4 \quad 4 \quad 3 \quad 2 \quad 1$

8. Often the health professional was not sure what my needs were (e.g., reassurance, support,

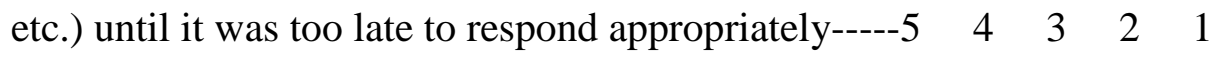

9. The health professional could accurately perceive my intentions quite well-----5 $\quad 4 \quad 4 \quad 3 \quad 2$ 1

10. The health professional paid close attention to what I said and did and tied to obtain as much as information he or she could-----5 $\quad 4 \quad 3 \quad 3 \quad 2 \quad 1$

The purpose of this questionnaire is to obtain your views about communication during your encounter with the health professionals at Student Health Service. You will be asked to make judgement of the health professionals' communication. For each item, circle the alternative that best describe how you feel. If you do not believe an item applies to this particular situation, please write NA next to the item. Use 7-Strongly Agree; 6-Slightly Agree; 5-Agree; 4-Not Sure; 3-Slightly Disagree; 2-Strongly Disagree; 1-Disagree.

The health professional explained the following to my satisfaction:

1. What my medical problem was.

2. The causes of my medical problem.

3. What I could do to get better.

4. The benefits and disadvantages of treatment choices (that is, the choices about what I could do to get better).

5. The purpose of any of the tests that were needed.

6. How prescribed medicine would help my problem.

7. How to take prescribed medicine. 
8. The possible side effects from the medicine.

9. The long-term consequences of my medical problem.

The health professional did a good job:

10. Reviewing or repeating important information.

11. Making sure I understood his/her explanation.

12. Making sure I understood his/her direction

13. Using language I could understand

14. Checking his/her understanding of what I said

15. Asking me questions related to my medical problem.

16. Asking me questions in a clear, understandable manner.

17. Asking questions that allowed me to elaborate on details.

18. Being warm and friendly

19. Contributing to a trusting relationship

20. Showing he/she cared about me

21. Making me relaxed or comfortable

22. Showing compassion

23. Being open and honest

Please indicate on the six items below how you feel about the quality of healthcare you have received. Circle one, and only one, response for each item. The middle score (4) indicates you are undecided. Score numbers closer to the adjective you think is most representative of your view indicate stronger views.

1. High Quality 1234567 Low Quality

2. Personable 1234567 Impersonal 
3. Uncaring 1234567 Caring

4. Concerned 1234567 Unconcerned

5. Beneficial 1234567 Not Beneficial

6. Unsatisfactory 1234567 Satisfactory

\section{Demographic Information}

1. Do you identify as?

Male

__ Female

_ Transgendered

__ Prefer not to disclose

2. Please indicate your year in school.

_Freshman

__ Sophomore

_. Junior

_ Senior

__ Graduate Student

__other

3. Age

4. Country of Origin/Nationality 